\title{
Correlation between the initial CT chest findings and short-term prognosis in Egyptian patients with COVID-19 pneumonia
}

\author{
Mohamed Mohamed Hefeda ${ }^{{ }^{*}}$ (E), Dalia Ezzat Elsharawy ${ }^{2}$ and Tamer Mahmoud Dawoud ${ }^{1}$
}

\begin{abstract}
Background: The recent pandemic of COVID-19 has thrown the world into chaos due to its high rate of transmissions. This study aimed to highlight the encountered CT findings in 910 patients with COVID-19 pneumonia in Egypt including the mean severity score and also correlation between the initial CT finding and the short-term prognosis in 320 patients.

Results: All patients had confirmed COVID-19 infection. Non-contrast CT chest was performed for all cases; in addition, the correlation between each CT finding and disease severity or the short-term prognosis was reported. The mean age was higher for patients with unfavorable prognosis $(P<0.01)$. The patchy pattern was the most common, found in 532/910 patients (58.4\%), the nodular pattern was the least common 123/910 (13.5\%). The diffuse pattern was reported in 124 (13.6\%). The ground glass density was the most common reported density in the study 512/910 (56.2\%). The crazy pavement sign was reported more frequently in patients required hospitalization or ICU and was reported in 53 (56.9\%) of patients required hospitalization and in 29 (40.2\%) patients needed ICU, and it was reported in 11 (39.2\%) deceased patients. Air bronchogram was reported more frequently in patients with poor prognosis than patients with good prognosis (16/100; 26\% Vs 12/220; 5.4\%). The mean CT severity score for patients with poor prognosis was 15.2. The mean $\mathrm{CT}$ severity score for patients with good prognosis 8.7., with statistically significant difference $(P=0.001)$.

Conclusion: Our results confirm the important role of the initial CT findings in the prediction of clinical outcome and short-term prognosis. Some signs like subpleural lines, halo sign, reversed halo sign and nodular shape of the lesions predict mild disease and favorable prognosis. The crazy paving sign, dense vessel sign, consolidation, diffuse shape and high severity score predict more severe disease and probably warrant early hospitalization. The high severity score is most important in prediction of unfavorable prognosis. The nodular shape of the lesions is the most important predictor of good prognosis.
\end{abstract}

Keywords: COVOD-19, COVID-19 chest CT, COVID-19 pneumonia, COVID-19 prognosis, COVID-19 CT severity score

\section{Introduction}

On December 31, 2019, China reported to the WHO the appearance of respiratory illness in a cluster of people in Wuhan city. On January 12, 2020, the WHO confirmed that a novel corona virus was the cause of the illness [1]. In Egypt, the first case was announced February 12, 2020 and second case on 1 March. As of December 3, 117,158 confirmed cases with $5.7 \%$ mortality rate in all Egyptian territories [2].

\footnotetext{
*Correspondence: mohamedhefeda@yahoo.com

${ }^{1}$ Radiology Department, Faculty of Medicine, Tanta University, Tanta,

Egypt

Full list of author information is available at the end of the article
}

(c) The Author(s) 2022. Open Access This article is licensed under a Creative Commons Attribution 4.0 International License, which permits use, sharing, adaptation, distribution and reproduction in any medium or format, as long as you give appropriate credit to the original author(s) and the source, provide a link to the Creative Commons licence, and indicate if changes were made. The images or other third party material in this article are included in the article's Creative Commons licence, unless indicated otherwise in a credit line to the material. If material is not included in the article's Creative Commons licence and your intended use is not permitted by statutory regulation or exceeds the permitted use, you will need to obtain permission directly from the copyright holder. To view a copy of this licence, visit http://creativecommons.org/licenses/by/4.0/. 
Though the microbiological tests especially reversetranscriptase polymerase chain reaction (RT-PCR) are considered the gold standard test for diagnosis of COVID-19 infection, yet, the sensitivity of the RT-PCR is not perfect (only about $89 \%$ ), and negative result do not exclude COVID-19 pneumonia [3, 4]. Also, false positive results were reported owing to technical errors [5].

From the start of the pandemic, CT has been used as complementary to RT-PCR in the diagnosis and management of COVID-19 pneumonia. Numerous reports and studies described the CT findings of COVID-19 pneumonia. The typical CT findings included ground glass opacities, consolidation, vascular enlargement, air bronchogram, crazy pavement sign, halo signs and reversed halo sign [6-21], with the distribution of the abnormalities was mostly bilateral, in the lower lobes, peripheral and sub-pleural [22]. Most reports described CT chest findings in patients from China or Europe and only few reports described CT chest finding in African countries [23-27]. It is unclear if the disease has the same CT characteristics as in different countries.

The prediction of mortality in COVID-19 pneumonia has relied on demographic and clinical factors like patient's age and associated co-morbidities [28, 29]. Identification of certain signs on initial CT chest examination may help to predict the prognosis and mortality in even young and healthy patients and may aid to detect the most vulnerable patients and consequently may change the treatment protocol and lines of management. Multiple studies have suggested different prognostic signs [30-33]. A semi-quantitative scoring system of lung involvement on $\mathrm{CT}$ has been suggested as useful marker in differentiation between severe illness group and other groups and is referred to as total severity score (TSS) [34].

The aim of this study was to describe the CT findings in Egyptian patients with confirmed COVID-19 pneumonia, and correlation between the initial chest CT findings and the CT severity score with short-term prognosis.

\section{Methods}

\section{Patients}

This retrospective study was approved by the institutional review board, and the informed consent was waived because of the outbreak of COVID-19.

The study included 910 consecutive patients, who were suspected to have COVID 19 pneumonia, in the time interval March 2, 2020, to November 18, 2020. CT beside laboratory test was used as screening tests for COVID 19 pneumonia. All patients included in the study subsequently performed reverse-transcription polymerase chain reaction (RT-PCR) in nasal-pharyngeal swabs and were found to be positive. After one month we could follow 320 patients either by phone, direct contact or rescanning for correlation of the initial CT findings with the clinical course. If the patient had multiple CT scans, the CT scan interpreted was only the initial CT scan. The time interval from the initial symptoms was from 1 to 8 days. We excluded all patients with initially normal CT scan and patients with all co-morbidities were included in the study.

Clinically, patients were categorized into 4 groups: Patients with mild symptoms who treated at home, stable patients treated in hospitals, critical patients needed ICU, and patients who died. The first two groups are considered good prognosis and the other two groups are considered poor prognosis.

\section{High-resolution CT imaging}

All high-resolution CT scans were obtained using SOMATOM Emotion 16 slices (Siemens, Germany). Images were acquired using following parameters: 2-4 mm section thickness, with axial reconstruction in $1 \mathrm{~mm}$ thickness; $20-40 \mathrm{mAs} ; 120-150 \mathrm{kV}$. The collimation width was $0.7 \mathrm{~mm}$. The acquisition range was from thoracic inlet to below the diaphragm by $5 \mathrm{~cm}$. Multiplane reconstruction (MPR) in sagittal and coronal planes technology was performed with a slice thickness of $2 \mathrm{~mm}$. The patients were laid supine, with the arms extended and if possible they were asked to hold breath. The recommended infection prevention and control measures were taken in all cases, including prompt sanitation of CT facility and the entire room.

The images were assessed with window width 1200$2000 \mathrm{HU}, 500-700 \mathrm{HU}$ Window level for lung window and window width 300-400/window level 30-40 HU for mediastinal window.

\section{CT chest imaging interpretation}

All the CT images of all patients were analyzed by two radiologists with 20 and 10 years of chest $\mathrm{CT}$ experience independently, blinded to the clinical data, and laboratory indicators, in a standard clinical picture Archiving and Diagnostic System workstation, and final decisions reached by consensus are reported.

The following CT features were assessed: distribution pattern: unilateral or bilateral, number of lobes involved (one, two, or more); the density of the lesions (groundglass opacity [GGO], consolidation, or GGO with consolidation); shape of the lesions: diffuse, patchy, nodular 
or mixed. Different signs: crazy paving pattern (ground glass opacity with superimposed interlobular septal thickening), sub-pleural transverse lines, halo sign (circular area of ground glass attenuation surrounding pulmonary nodule), reversed halo sign (central area of ground glass opacity surrounded by area of consolidation), large vessel sign (vessel diameter larger than expected), dense vessel sign (vessels denser than expected in non-contrast study), mediastinal lymph node enlargement, and pleural effusion.

\section{CT severity score (CT-SS)}

In the current study, we adopted the semi-quantitative scoring system proposed by Pan et al. [35] was used to assess volume of lung involved. Each of the five lung lobes was subjectively scored on a scale of $0-5$, with 0 indicating no involvement, 1 equals less than $5 \%$ involvement, 2 when 5-25\% involvement, 3 when $26-49 \%$ involvement, 4 when $50-75 \%$ involvement, and 5 indicating more than $75 \%$ involvement. The total CT score was the sum of the individual lobar scores and ranged from 0 (no involvement) to 25 (maximum involvement).

Mild severity when the score is $1-8$. Moderate severity score 9-17, severe disease 18-25 score.

\section{Statistical analyses}

Statistical analysis was performed with SPSS (Version 23.0, IBM Corp., USA). Categorical variables are

Table 1 Demographic data in all 910 patients with COVID-19 pneumonia and correlation with prognosis in 320 patients

\begin{tabular}{|c|c|c|c|c|c|c|}
\hline & All patients (910) & $\begin{array}{l}\text { Stable patients } \\
(127 / 320)\end{array}$ & $\begin{array}{l}\text { Hospitalized stable } \\
\text { patients }(93 / 320)\end{array}$ & $\begin{array}{l}\text { Patients needed } \\
\text { ICU }(72 / 320)\end{array}$ & Died (28/320) & $P$ value \\
\hline \multicolumn{7}{|l|}{ Age } \\
\hline Median & 55.2 & 36.5 & 42.4 & 51.4 & 57.7 & $<0.01$ \\
\hline Range & $(19-90)$ & $(19-72)$ & $(34-71)$ & $(40-75)$ & $38-87$ & \\
\hline \multicolumn{7}{|l|}{ Gender } \\
\hline Male & $528(58.02 \%)$ & $61(48.03 \%)$ & $57(61.29 \%)$ & $38(52.77 \%)$ & $17(60.71 \%)$ & $>0.05$ \\
\hline Female & 382 (41.97\%) & $65(51.18 \%)$ & $36(38.79 \%)$ & $34(47.22 \%)$ & $11(39.28 \%)$ & \\
\hline \multicolumn{7}{|l|}{ Clinical } \\
\hline Fever & 802 (88.13\%) & $102(80.03 \%)$ & $87(93.54 \%)$ & $68(94.44 \%)$ & $28(100 \%)$ & 0.651 \\
\hline Cough & 765 (84.06\%) & $97(76.3 \%)$ & 65 (69.89\%) & $65(90.27 \%)$ & $26(92.85 \%)$ & 0.45 \\
\hline Dyspnea & 412 (45.27\%) & 19(14.96) & $56(60.21 \%)$ & $54(75.00 \%)$ & $28(100 \%)$ & $<0.05$ \\
\hline Sore throat & $350(38.46 \%)$ & $28(22.04 \%)$ & $38(40.86 \%)$ & $23(31.94 \%)$ & $11(39.28 \%)$ & 0.541 \\
\hline GIT symptoms & $137(15.05 \%)$ & $35(27.55 \%)$ & $23(24.73 \%)$ & $18(25.00 \%)$ & $8(28.57 \%)$ & 0.432 \\
\hline Muscle pain & $522(57.36 \%)$ & $58(45.66 \%)$ & $54(58.06 \%)$ & $61(84.72 \%)$ & $22(78.5 \%)$ & 0.58 \\
\hline \multicolumn{7}{|l|}{ Laboratory investigations } \\
\hline SP O2 (\%) & 91 (62-99) & 93 (80-99) & $88(75-98)$ & 72 (80-99) & $69(62-81)$ & 0.01 \\
\hline Lymphocytes (\%) & $14.8 \%(3.2-49.5)$ & $15.2(6-49.5)$ & $12.2(4.4-45.5)$ & $10.2(5.3-40.5)$ & $8.2(3.2-11.45)$ & 0.07 \\
\hline CRP $(\mathrm{mg} / \mathrm{dL})$ & $13.54(1.1-52.16)$ & $7.5(1.1-16.3)$ & $11.5(8.2-46.3)$ & $16.5(8.1-36.3)$ & 18.5(9.1-52.16) & 0.01 \\
\hline D-Dimer (mg/L) & $0.95(0.27-33.2)$ & $0.71(0.28-9.3)$ & $0.99(0.3-15.3)$ & $1.1(1.8-7.3)$ & $2.3(1.21-13.3)$ & $<0.05$ \\
\hline Leucocytes $\left(10^{3} \mu \mathrm{L}\right)$ & $5.91(2.1-19.12)$ & $4.5(3.3-17.2)$ & $8.5(2.1-12.2)$ & 7.5(5.4-19.12) & $11.5(7.3-12.2)$ & 0.56 \\
\hline S creatinine (mg/dL) & $0.87(0.50-8.26)$ & $0.75(0.50-1.4)$ & $0.81(0.61-1.9)$ & $1.5(0.80-8.2)$ & $2.15(0.50-1.4)$ & 0.01 \\
\hline Bilirubin (mg/dL) & $0.40(0.2-4.8)$ & $0.3(0.2-1.1)$ & $1.1(0.4-2.1)$ & $0.8(1.2-3.1)$ & $0.9(1.4-4.8)$ & 0.65 \\
\hline \multicolumn{7}{|l|}{ Co-morbidities } \\
\hline Diabetes & $166(18.2 \%)$ & $64(50.39 \%)$ & $31(33.3 \%)$ & 49 (68.05\%) & $13(46.4 \%)$ & 0.07 \\
\hline Hypertension & $171(18.7 \%)$ & $62(48.81 \%)$ & $34(36.95 \%)$ & $57(79.16 \%)$ & $9(32.1 \%)$ & 0.08 \\
\hline Heart disease & 49 (5.3\%) & $18(14.17 \%)$ & $16(17.20 \%)$ & $11(15.27 \%)$ & $4(14.28 \%)$ & 0.61 \\
\hline COPD/chest & $43(4.7 \%)$ & $15(11.81 \%)$ & $12(12.90 \%)$ & $10(13.8 \%)$ & $6(21.4 \%)$ & 0.54 \\
\hline Neurological & $31(3.4 \%)$ & $13(10.23 \%)$ & $9(9.6 \%)$ & $5(6.9 \%)$ & $4(14.2 \%)$ & 0.27 \\
\hline
\end{tabular}


expressed as number percentages. The diagnosis accuracy between HRCT features combined with epidemiological history and the first detection of viral nucleic acid was compared using $\mathrm{X} 2$ test or Fisher's exact test. A $P$ value $<0.05$ was considered statistically significant.

\section{Results}

\section{Patient demographics, clinical and laboratory findings}

The patient's clinical and laboratory findings and the associated Co-morbidities are summarized in Table 1. The study included 910 patients (median age 55 years; range $19-90$ years old), 582 (58.03) were males and 382 $(41.97 \%)$ were females. We could follow the short-term prognosis of 320 patients. The correlation between the clinical data and the short-term prognosis is summarized in Table 1.

The mean age was higher for patients with unfavorable prognosis $(P<0.01)$. No gender predicts bad prognosis.
No symptoms predicted prognosis except dyspnea which is mildly more common in patients with poor prognosis. On the other hand laboratory findings showed significant difference between patients with good and poor prognosis. The oxygen saturation SP O2 was significantly lower in patients with bad prognosis than patients with good prognosis ( $P$ value 0.01 ). The mean CRP, D-Dimer and $S$ creatinine were significantly higher in patients with poor prognosis ( $P$ values $0.01,<0.05$ and 0.01 , respectively). No co-morbidities were associated with poor prognosis in the current study.

\section{CT chest findings}

In the 910 patients initially studied for Covid-19 pneumonia, most lesions were bilateral (808 patients, $88.8 \%$ ), most patients in all groups were bilateral, with no significant difference between the patients with good prognosis and poor prognosis. Most patients involved in the study had lesions in three lobes or more, with only 179/910

Table 2 Chest CT findings in all patients

\begin{tabular}{|c|c|c|c|c|c|c|}
\hline & All patients (910) & $\begin{array}{l}\text { Stable patients } \\
(127 / 320)\end{array}$ & $\begin{array}{l}\text { Hospitalized stable } \\
\text { patients }(93 / 320)\end{array}$ & $\begin{array}{l}\text { Patients needed } \\
\text { ICU }(72 / 320)\end{array}$ & Died (28/320) & $P$ value \\
\hline Distribution & & & & & & 0.71 \\
\hline Bilateral & $808(88.8 \%)$ & $104(81.8 \%)$ & $81(87.1 \%)$ & $69(95.8 \%)$ & $28(100 \%)$ & \\
\hline Unilateral & $102(11.2 \%)$ & $23(18.1 \%)$ & $12(12.9 \%)$ & $3(4.1 \%)$ & (0\%) & \\
\hline No of segments involved & & & & & & 0.01 \\
\hline One & $43(4.7 \%)$ & $13(10.2 \%)$ & $5(5.3 \%)$ & $0(0 \%)$ & $0(0 \%)$ & \\
\hline Two & $136(14.9 \%)$ & $22(17.3 \%)$ & $7(7.5 \%)$ & $3(4.1 .1 \%)$ & $0(0 \%)$ & \\
\hline Three & $198(21.7 \%)$ & $24(18.9 \%)$ & $12(12.9 \%)$ & $6(8.3 \%)$ & $2(7.1 \%)$ & \\
\hline Four & $292(32.1 \%)$ & $46(36.2 \%)$ & $36(38.7 \%)$ & $11(15.2 \%)$ & $5(17.8 \%)$ & \\
\hline Five & $246(27.04 \%)$ & $22(17.3 \%)$ & $33(35.4 \%)$ & $53(73.6 \%)$ & $21(75 \%)$ & \\
\hline \multicolumn{7}{|l|}{ Shape } \\
\hline Diffuse & $124(13.6 \%)$ & $21(16.5 \%)$ & $23(24.7 \%)$ & 28(38.4\%) & $11(42.8 \%)$ & 0.01 \\
\hline Peripheral & $89(9.7 \%)$ & $17(13.3 \%)$ & $22(23.6 \%)$ & $20(27.4 \%)$ & $6(21.4 \%)$ & 0.53 \\
\hline Peripheral and central & $30(3.2 \%)$ & $4(3.1 \%)$ & $1(1.1 \%)$ & $7(9.6 \%)$ & $4(14.2 \%)$ & 0.02 \\
\hline Central & $5(0.05 \%)$ & $-(0 \%)$ & $-(0 \%)$ & $1(1.3 \%)$ & $1(3.5 \%)$ & 0.01 \\
\hline Patchy & $532(58.4 \%)$ & $63(49.6 \%)$ & $42(45.1 \%)$ & $38(52.7 \%)$ & 16(57.1\%) & 0.54 \\
\hline Nodular & $123(13.5 \%)$ & $26(20.7 \%)$ & 13(13.9\%) & $1(1.3 \%)$ & $-(0 \%)$ & 0.001 \\
\hline Mixed & $131(14.3 \%)$ & 17(13.3\%) & 15(16.1\%) & $5(6.9 \%)$ & $1(3.5 \%)$ & 0.01 \\
\hline \multicolumn{7}{|l|}{ Density } \\
\hline GGO & $512(56.2 \%)$ & $96(75.5 \%)$ & $44(58.1 \%)$ & $32(43.8 \%)$ & $11(39.3 \%)$ & 0.081 \\
\hline Consolidation & $178(19.5 \%)$ & $4(3.1 \%)$ & 10(10.7\%) & $9(12.3 \%)$ & $8(28.6 \%)$ & 0.03 \\
\hline Mixed & $220(24.1 \%)$ & 23(18.1\%) & $29(31.2 \%)$ & $31(42.5 \%)$ & $9(32.1 \%)$ & $<0.05$ \\
\hline
\end{tabular}




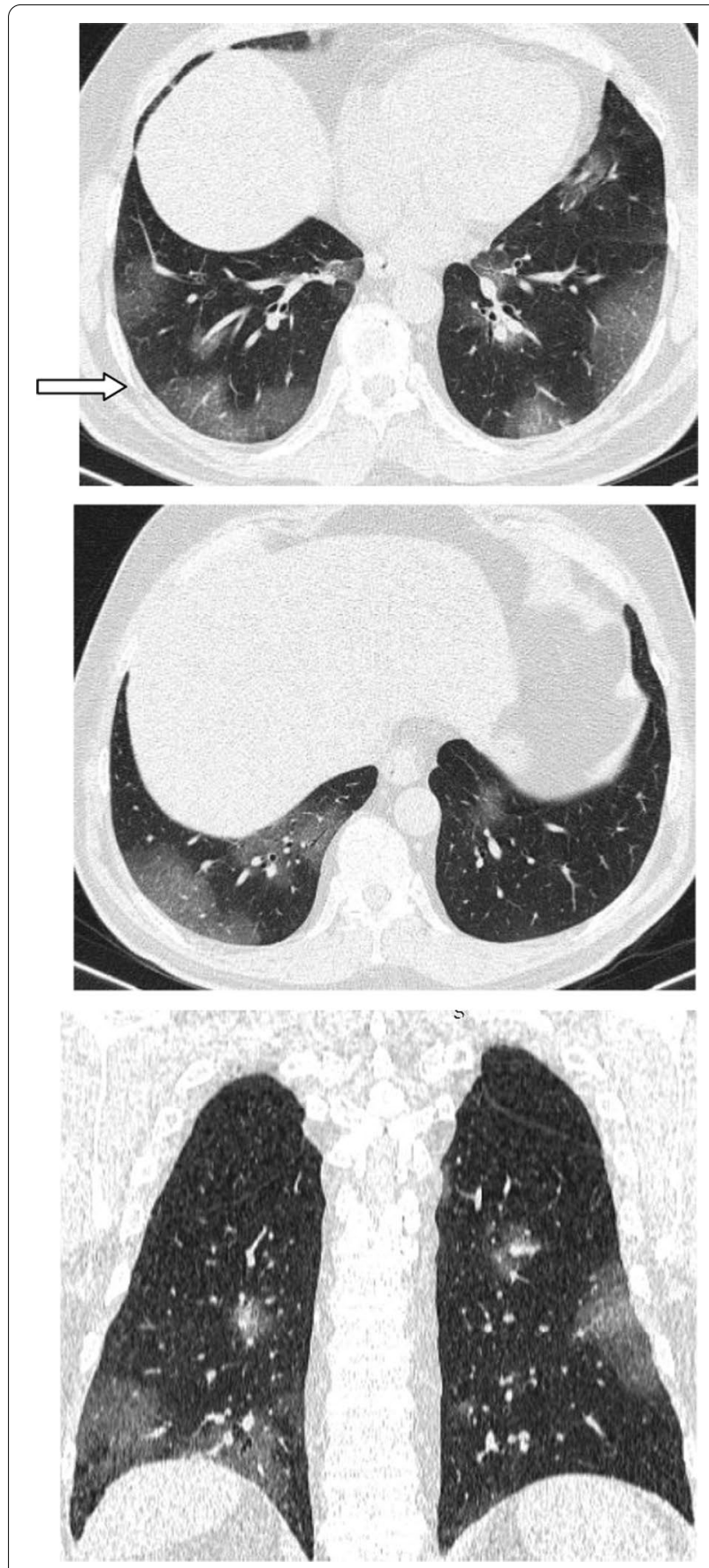

Fig. 1 Male patient, age 34 years, with pure ground glass opacities scattered in both lungs. All lesions showed patchy shape
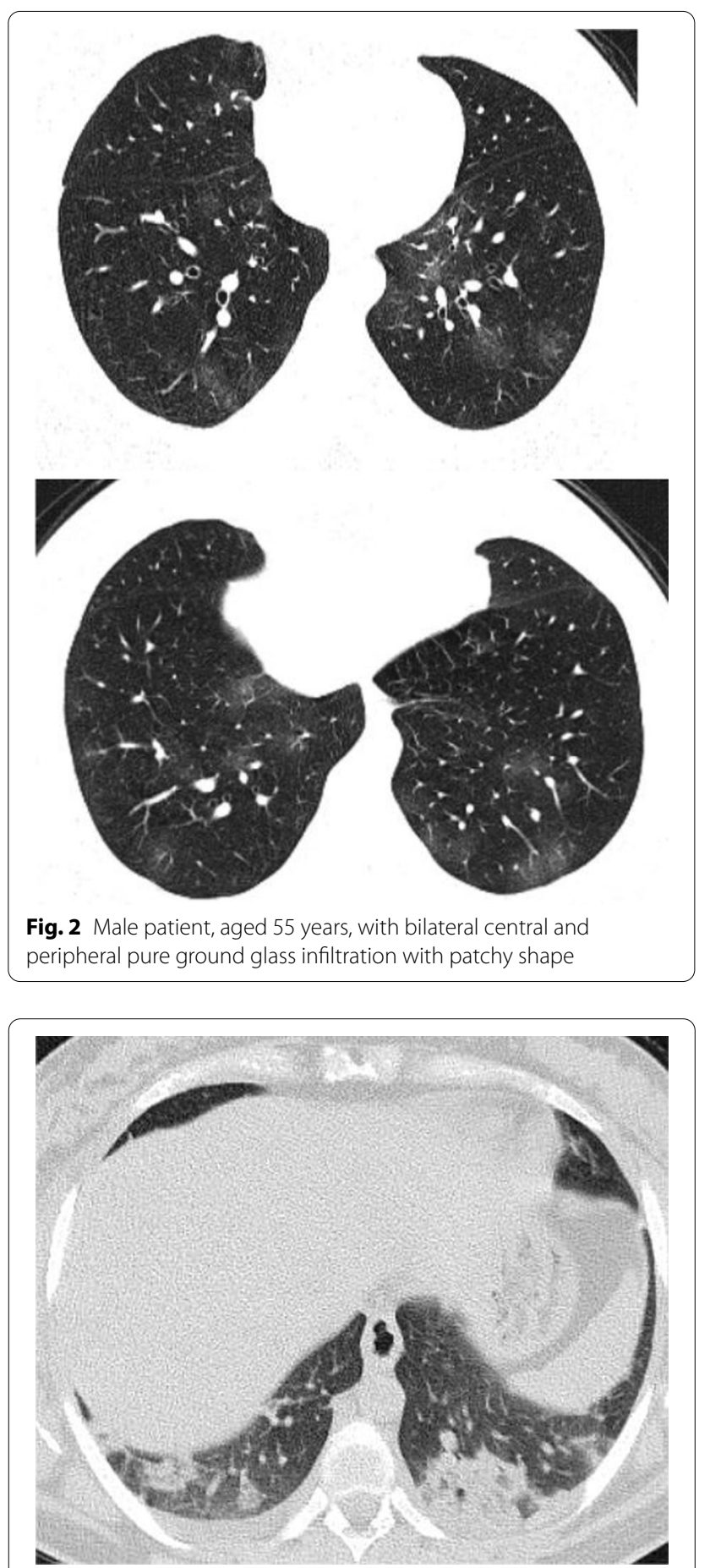

Fig. 3 Female patient, aged 35 years, after 7 days from onset of fever. Bilateral lower lobes patchy areas of consolidation with air bronchogram and mild right pleural effusion 

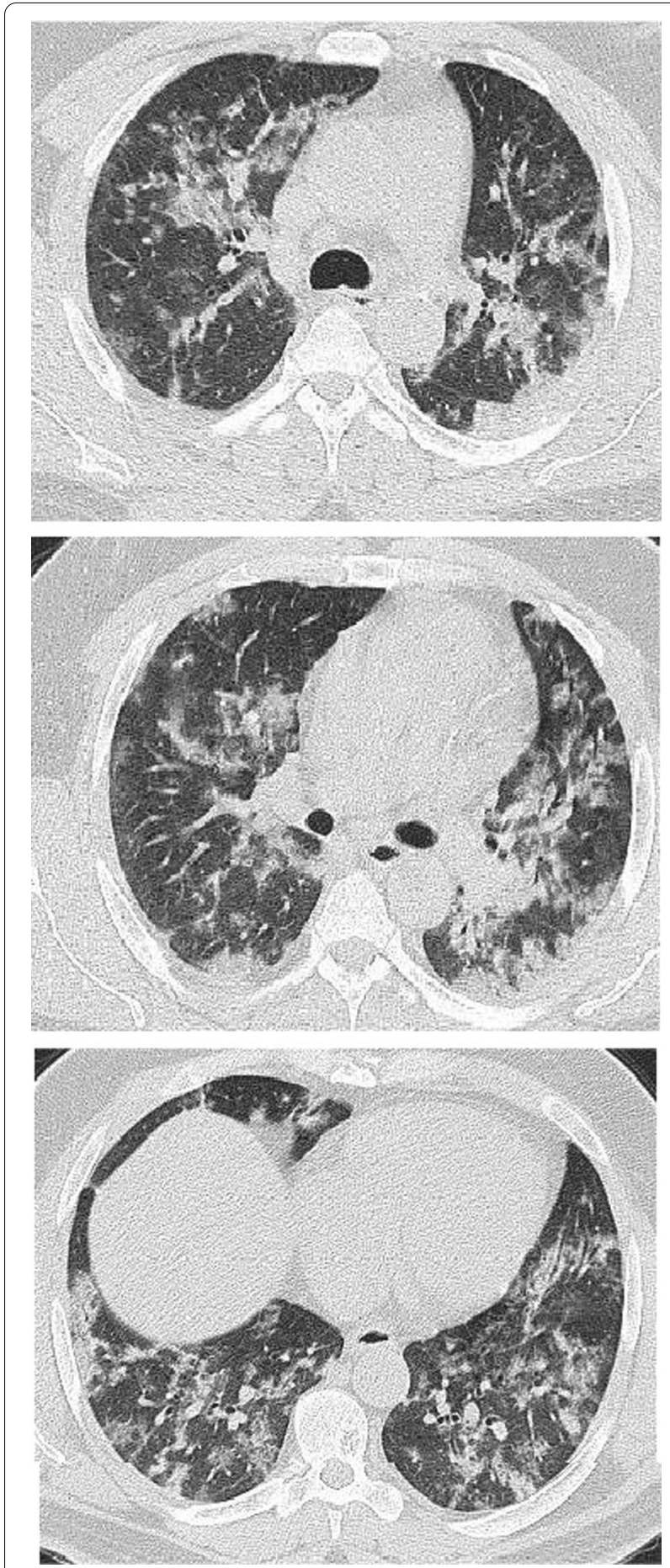

Fig. 4 Male patient aged 57 years, 11 days after the onset of

symptoms. Mixed patchy consolidation and ground glass infiltration

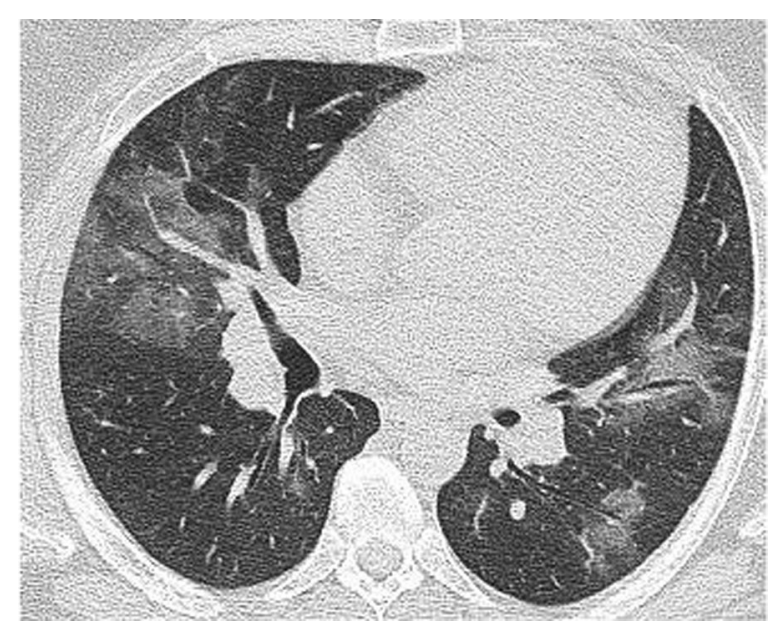

Fig. 5 Male patient, aged 62 years four days from onset of symptoms. Wide patches of ground glass infiltration and dense large vessels
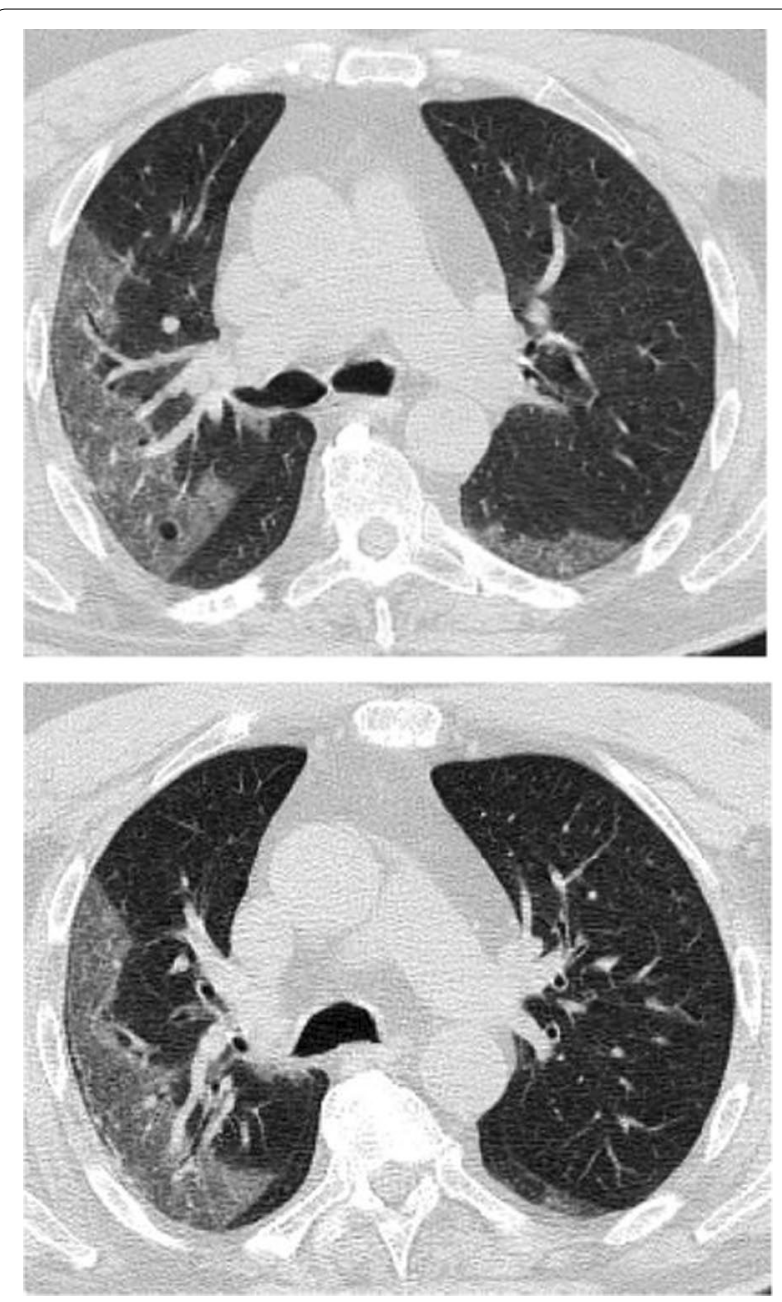

Fig. 6 Male patient aged 43 years, with diffuse peripheral ground glass infiltration with dense and large vessels 


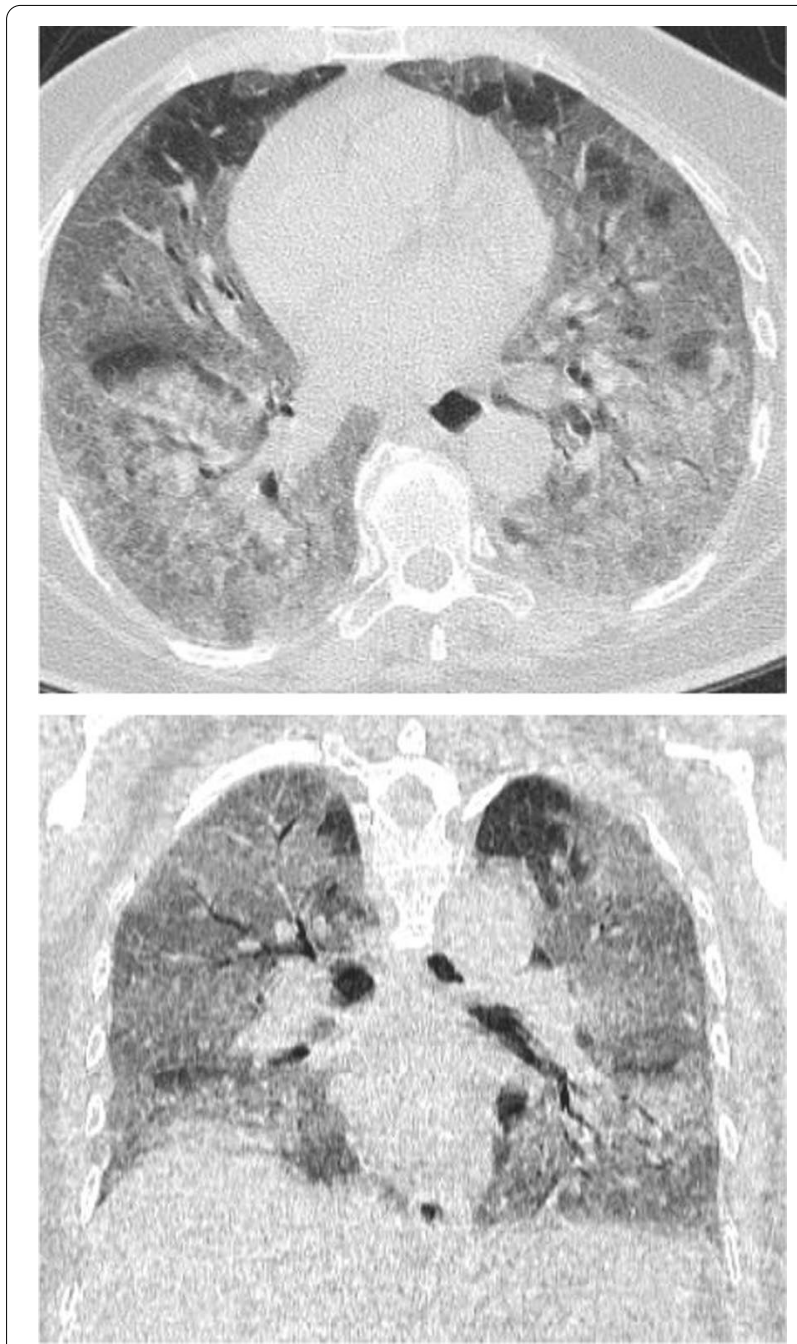

Fig. 7 Female patient aged 71 years, with fever, dyspnea and neurological manifestations. Diffuse central and peripheral ground glass infiltration mounting to whitening out of the lung parenchyma. The $C T$ severity score was 23

(19.6\%) having lesions in one or two lobes. Patients with un-favorable prognosis tend to have more lobe involved than patients with good prognosis with significant difference $(P=0.01)$ (Table 2$)$.

Regarding the shape and pattern of the lesions, the patchy pattern (Figs. 1, 2, 3, 4, 5) was the most common, found in 532/910 patients (58.4\%), the nodular pattern was the least common 123/910 (13.5\%). The diffuse pattern was reported in 124 (13.6\%). The diffuse pattern is generally associated with poor prognosis (Figs. 6, 7),
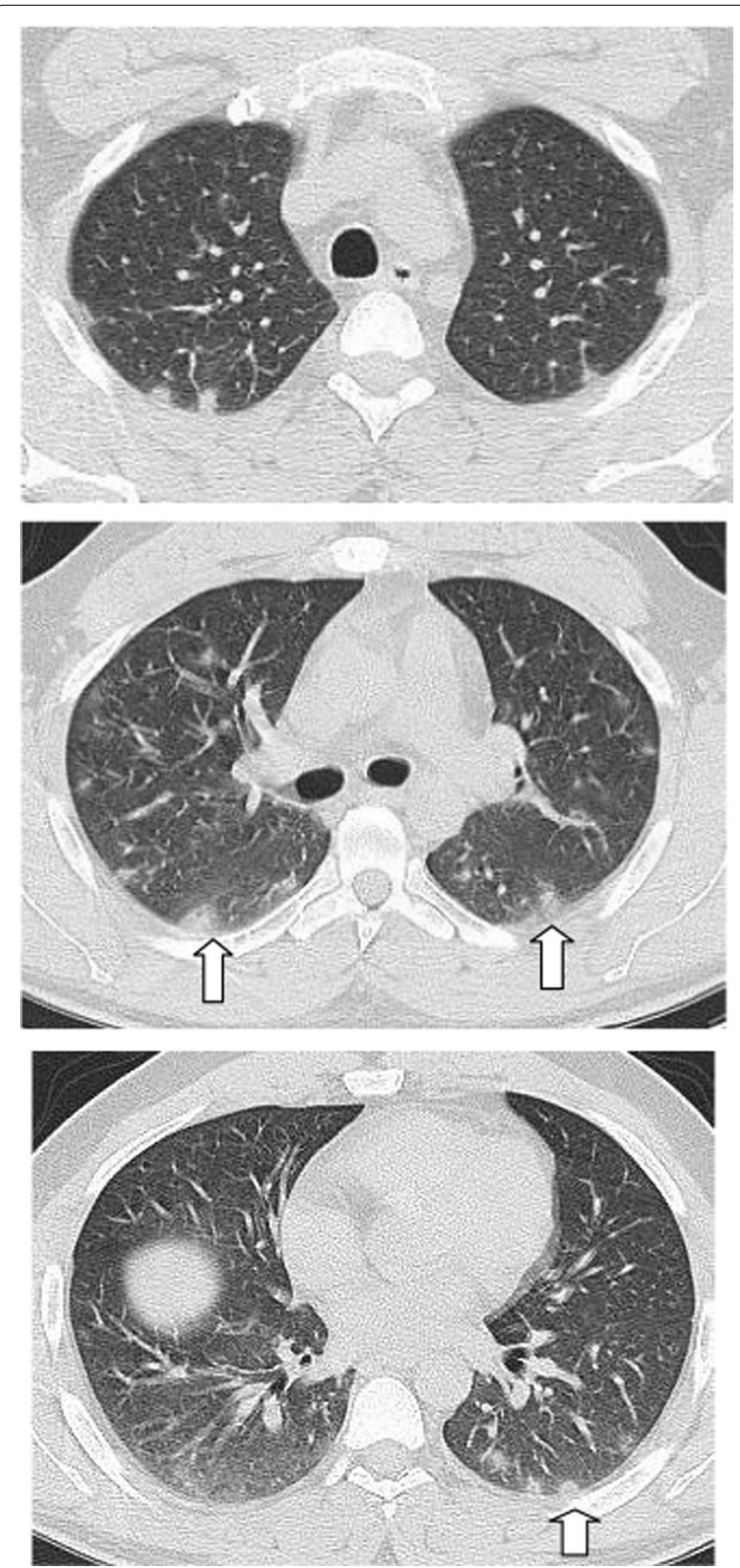

Fig. 8 Male patient 22 years, 3 days after the onset of symptoms. Multiple peripheral subpleural nodules, with no cavitation or cystic changes. Patient received treatment at home

especially if the central zones are involved (Table 2). Interestingly, patients with nodular pattern either alone or associated with patchy pattern (mixed pattern) had a good prognosis (Figs. 8, 9, 10, 11, 12), with statistically 

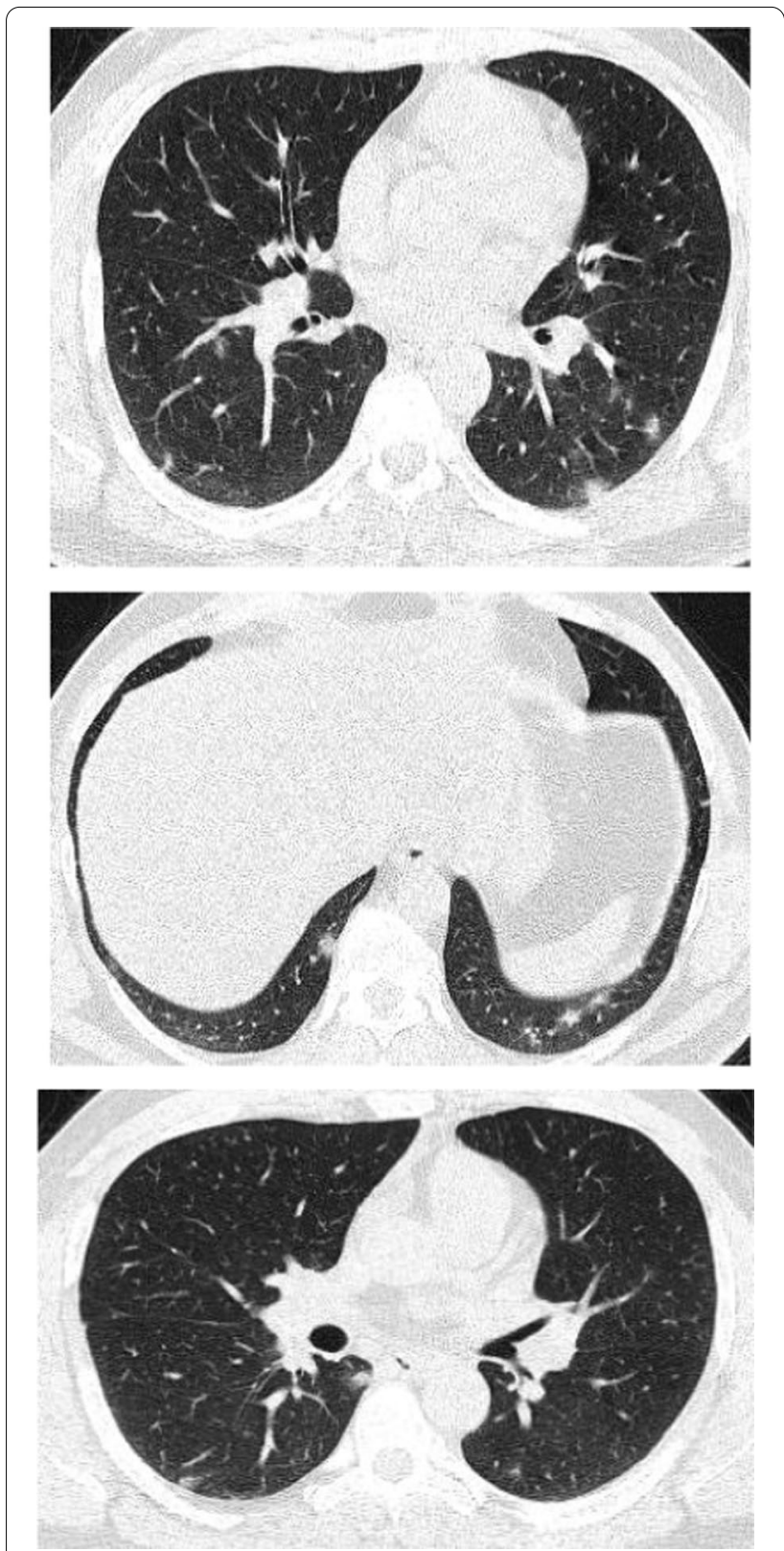

Fig. 9 Male patient, aged 35 years, with fever for 6 days. Multiple small nodular shadows in both lungs, predominantly subpleural

significant difference $(0.001$ and 0.01$)$. The patchy pattern had no significant difference between the patients with good prognosis and patients with poor prognosis $(P=0.54)$.

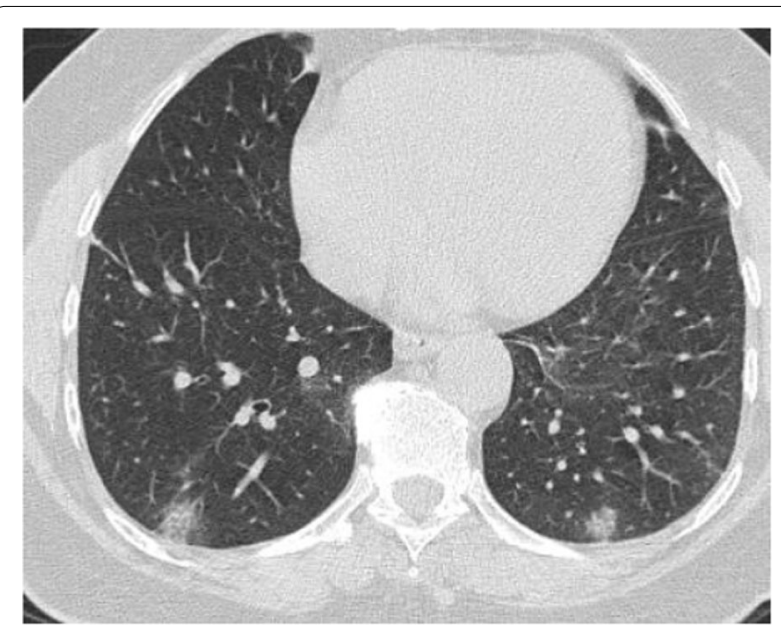

Fig. 10 Male patient, aged 28 years, Nodular shape of the lesions. The nodular pattern carried a good prognosis in the current study

The ground glass density was the most common reported density in the study 512/910 (56.2\%), but it was present in the good and poor prognosis, with no significant difference. On the other hand, the consolidation either if present alone or associated with ground glass opacity was associated with poor prognosis with statistically significant difference ( 0.03 and $<0.05$, respectively).

Multiple associated signs were reported. The halo sign and reversed halo were reported in $12.8 \%$ and $10.1 \%$ of the patients included in the study, respectively. Both signs were reported more frequently in patients with good prognosis, with statistically significant difference ( $P$ value 0.001$)$. Also the transverse sub-pleural lines were associated with good prognosis. The transverse sub-pleural lines were a relatively common sign in the current study, reported in $317(34.8 \%)$ of the involved patients. It was reported in $71 / 220(32.3 \%)$ patients with favorable prognosis and only $7 / 100$ (7\%) of patients with unfavorable prognosis, with statistically significant difference ( $P$ value 0.01$)$. The crazy pavement sign (Fig. 13) reported in $376(41.3 \%$ ) of the involved patients. The crazy pavement sign was reported more frequently in patients required hospitalization or ICU and was reported in 53 (56.9\%) of patients required hospitalization, and it was reported in 11 (39.2\%) deceased patients. Also air bronchogram was reported more frequently in patients with poor 

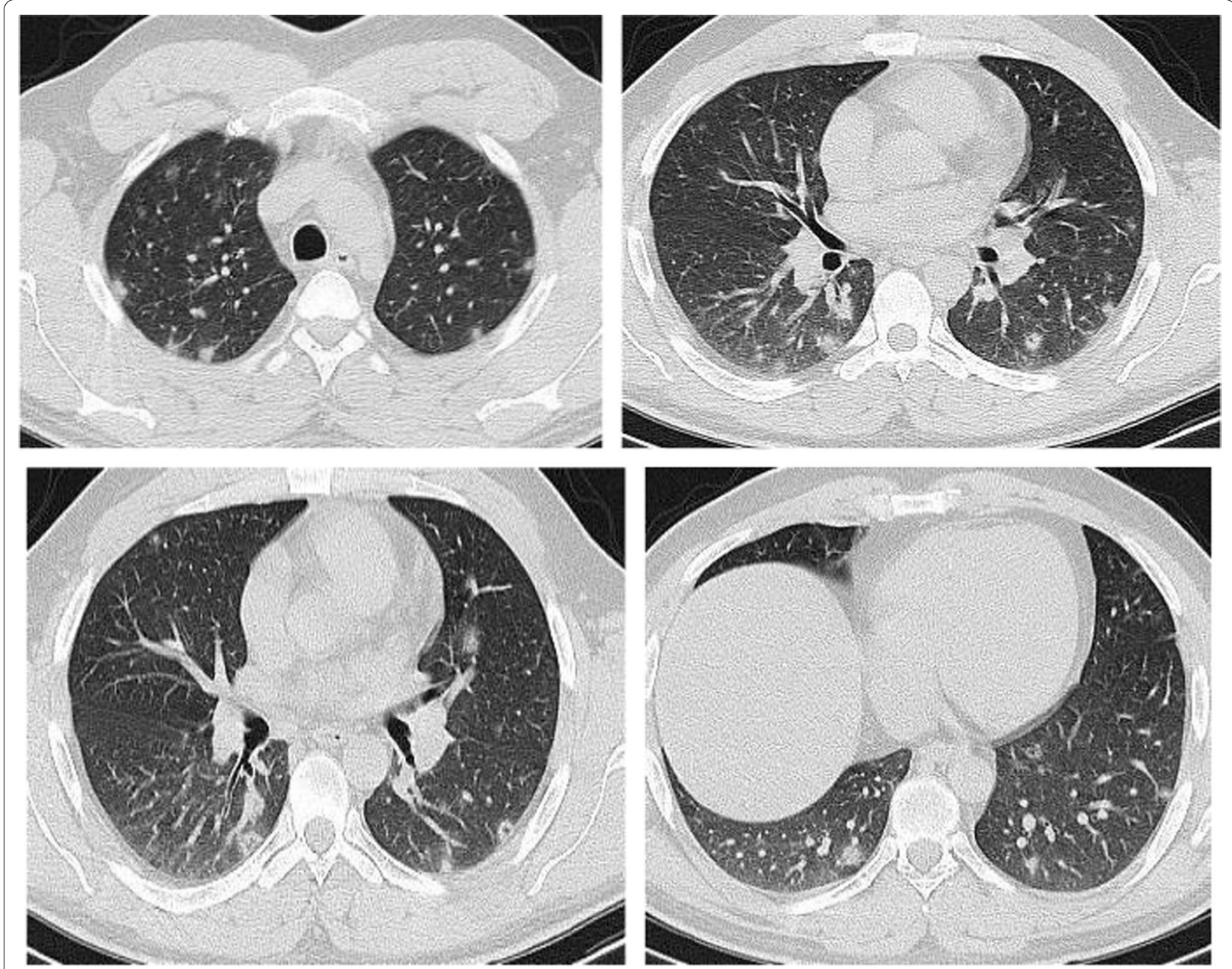

Fig. 11 Male patients, 23 years old, with fever and cough for 4 days. Predominantly nodular pattern, with small cavitary lesions/cystic changes

prognosis than patients with good prognosis $(16 / 100$; $16 \%$ Vs $12 / 220 ; 5.4 \%)$ with statistically significant difference. The pleural effusion, pericardial effusion and pneumo-mediastinum were associated with poor prognosis (Table 3).

The mean CT severity score for patients with poor prognosis was 15.2. The mean CT severity score for patients with good prognosis was 8.7., with statistically significant difference $(P=0.001)$. In the current study among the 320 patients we could follow their outcome, 147 had mild CT severity score (1-8), of them only $29(19.7 \%)$ had unfavorable prognosis and only
5 patient died with initial $\mathrm{CT}$ severity score $<8$. The patients with moderate $\mathrm{CT}$ severity score had no statistically significant difference between the patient's with good and poor prognosis. Most patients with severe CT severity score had unfavorable prognosis (38/59 patients; $64.4 \%)$. Of the 28 patients died in this study, $5(17.8 \%)$ had initial score $1-8,8$ patients $(28.5 \%)$ had score $9-17$ and 15 patients (53.3\%) had score $>17$. On the other hand of the 127 patients with mild symptoms and treated at home 73 patients $(57.5 \%)$ had score $1-8$; 49 patients $(38.6 \%)$ had score $9-17$ and only 5 patients (3.9\%) had score > 17 (Figs. 14, 15, 16, 17, 18, 19, 20). 

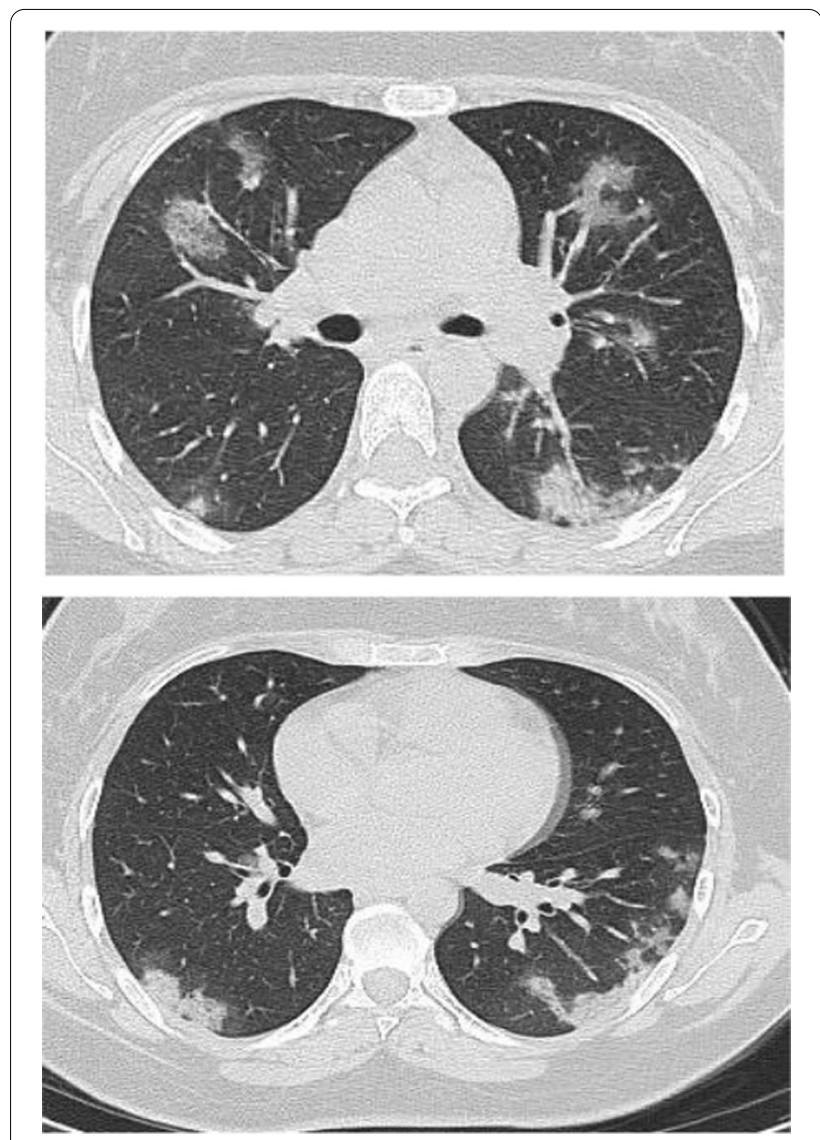

Fig. 12 Female patient, aged 27 years, with multiple patches of consolidation with mixed nodular and patchy shape

\section{Discussion}

COVID-19 is potentially fatal and highly contagious disease, both factors making it a significant public health problem. Early diagnosis and isolation are important in controlling the disease spread. In the current study we described the CT findings in 910 Egyptian patients [35] (Table 4).

In the current study, patients with older age, and patients with diabetes or hypertension had more severe clinical disease than younger patients and patients with co-morbidities. Also, patients with severe disease suffered from dyspnea more frequently than patients with mild forms. Patients with severe disease had different laboratory investigations especially higher CRP, D-Dimer and S-creatinine. The presence of dyspnea may indicate more damage of the alveoli or the presence of interstitial inflammatory response. High Serum CRP was found to be associated with poor outcome because it indicates diffuse and severe inflammatory reaction [36]. Also the increase in serum D-dimer was supposed to be mortality predictor as a consequence of disseminated coagulopathy [37].

The great majority of our patients had bilateral disease $(88.8 \%)$ and the abnormalities involved three segments or more (80.8\%). Our results are approximate to the meta-analysis of Garg et al. [38], with reported incidence of unilateral disease in $286 / 3141$ patients (9.1\%). Also, Adams et al. [22], in a meta-analysis including 3466 patients reported pooled prevalence of unilateral disease in $15 \%$ of the patients. In the current study, the prevalence of ground glass opacity, ground glass opacity and consolidation and consolidation only were $56.2 \%, 24.1 \%$ and $19.5 \%$, respectively, the prevalence and order are similar to previous reports from different countries [22, 38, 39].

Ground glass opacity is the earliest and most consistent sign in COVID-19 pneumonia. In literature, its incidence ranged from $65 \%-100 \%[6,7,40]$. The pathogenesis of GGO is presumed to be alveolar edema, alveolar exudate and hyaline membrane formation [41]. In the current study the general incidence of GGO was $80.5 \%$, because we included patients with early and late disease. We found no significant difference in the incidence of GGO between patients with favorable and unfavorable prognosis.

Consolidations either alone or with GGO reported in $43.6 \%$ of patients in the current study. Consolidations were reported in $47 \%$ of patients in the study by Wong et al. [42]. Zhou et al. [43] in a study involved 100 patients with duration of 1-7 days from the onset of symptoms reported GGO and consolidations in 43\% of patients. In another study Pan et al. [7] reported that the incidence of consolidation increases with the duration of symptoms. In the current study, consolidations either alone or with GGO were observed more frequently in patients with un-favorable prognosis with statistically significant difference. In a recent study, Zhan et al. [44] reported consolidation in $4.9 \%$ of mild pneumonia cases and $70.1 \%$ of cases with severe pneumonia $(P<0.017)$. 

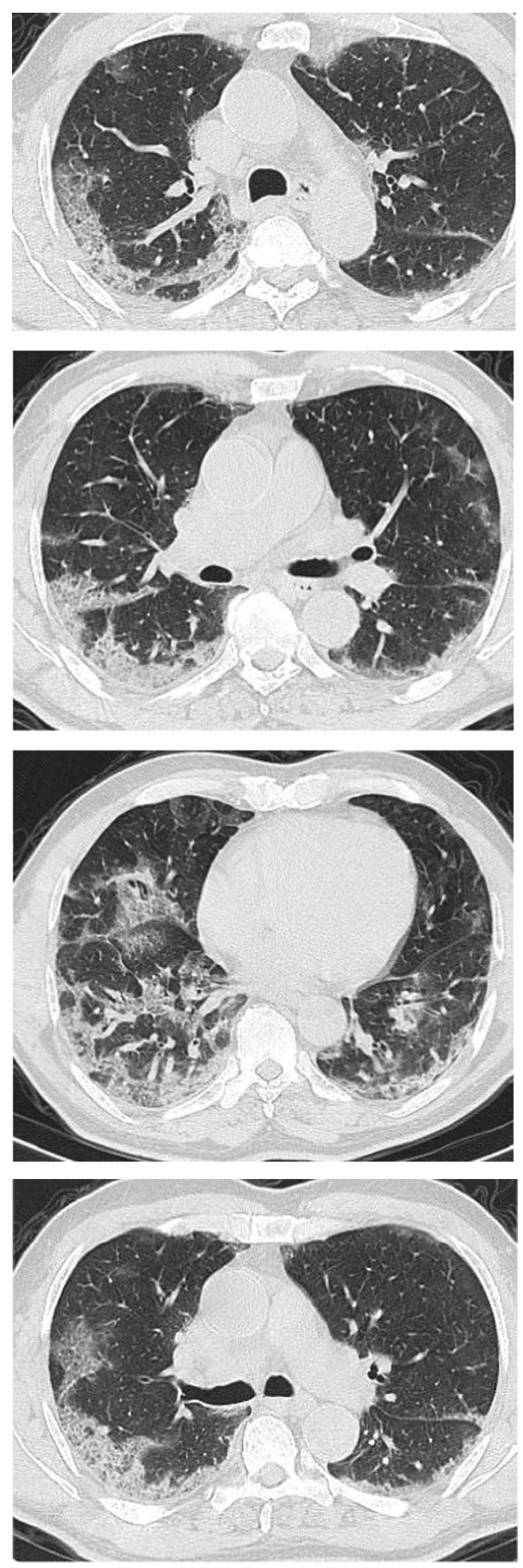

Fig. 13 Male patient aged 32 years, with wide areas of consolidation mainly peripheral and subpleural, with crazy pavement appearance. This pattern associated with high CT-SS carried unfavorable prognosis in the current study

Different shapes of the lesions were reported in our study, we found the rounded shape either alone or mixed with patchy shape were reported more frequently in stable patients with favorable prognosis, Diffuse pattern especially if central was associated with poor prognosis. Tabatabaei et al. [31] reported nodular shape in $26 \%$ of patients with nodular patients, and $8 \%$ of deceased patients, while the central involvement was reported in $85 \%$ of deceased patients and in $56 \%$ of patients needed inward hospitalization. Also Parry et al. [45] reported central lung involvement in $85 \%$ in unstable patients, with statistically significant difference with the stable group $(P<0.05 \%)$.

The crazy paving sign was reported in $41.3 \%$ of patients included in this study, and generally was reported in patients needed hospitalization or ICU. The crazy paving sign is presumed to reflect alveolar edema and interstitial inflammation, relatively a specific sign of COVID 19 pneumonia and reported in as high as $92 \%$ of cases [46, 47]. The initial reports suggested that crazy paving pattern is a sign of progressive disease [48, 49]. Zahan et al. [44], reported the incidence of localized crazy paving sign in $65 \%$ of patients with mild pneumonia cases and in $23.4 \%$ of the severe cases $(P<0.001)$. Meiler et al. [50] reported crazy paving sign as the only independent predictor of poor outcome by multivariable analysis and also predicted negative outcome by univariable analysis, and they suggested a correlation between its presence and the incidence of pulmonary edema and acute respiratory distress syndrome. Tabatabaei et al. [31] in a study included 120 patients noticed crazy paving sign more frequently in patients admitted to ICU and dead patients $(P<0.05)$.

The differential diagnosis of the halo sign [14-16] includes hemorrhagic nodules, fungal infection, metastasis, and viral infection [51]. The halo sign was reported in $12.8 \%$ of patients in the current study. The incidence in the literature ranged from $1.7-41.8 \%$ (with pooled incidence 23.7\%) [38]. Though the halo sign reflects alveolar edema, hemorrhage or microcirculation thrombosis, in the current study, halo signs were associated with good prognosis. 
Table 3 Associated CT signs in all patients

\begin{tabular}{|c|c|c|c|c|c|c|}
\hline & All patients (910) & $\begin{array}{l}\text { Stable patients } \\
(127 / 320)\end{array}$ & $\begin{array}{l}\text { Hospitalized stable } \\
\text { patients }(93 / 320)\end{array}$ & $\begin{array}{l}\text { Patients needed } \\
\text { ICU }(72 / 320)\end{array}$ & Died $(28 / 320)$ & $P$ value \\
\hline Air bronchogram & 134 (14.7\%) & $8(6.2 \%)$ & $4(4.3 \%)$ & $19(26.3 \%)$ & $7(25 \%)$ & $<0.01$ \\
\hline Halo sign & $117(12.8 \%)$ & $17(13.3 \%)$ & $18(19.3 \%)$ & $3(4.1 \%)$ & $-(0 \%)$ & 0.01 \\
\hline Reversed halo sign & $92(10.1 \%)$ & $19(14.9 \%)$ & $21(22.6 \%)$ & $8(10.9 \%)$ & $1(3.5 \%)$ & 0.02 \\
\hline Crazy Pavement pattern & $376(41.3 \%)$ & $22(17.3 \%)$ & $53(56.9 \%)$ & $29(40.2 \%)$ & $11(39.2 \%)$ & 0.002 \\
\hline Cavitation & $72(7.9 \%)$ & $11(8.6 \%)$ & $14(3.3 \%)$ & $7(9.7 \%)$ & $3(10.7 \%)$ & 0.51 \\
\hline Bronchiectasis & $29(3.1 \%)$ & $1(0.07 \%)$ & $-(0 \%)$ & $2(2.7 \%)$ & $2(7.1 \%)$ & 0.34 \\
\hline Pleural effusion & $37(4.06 \%)$ & $-(0 \%)$ & $-(0 \%)$ & $2(2.7 \%)$ & $2(7.1 \%)$ & 0.01 \\
\hline Pericardial effusion & $11(1.2 \%)$ & $-(0 \%)$ & $1(0.9 \%)$ & $1(1.3 \%)$ & $2(7.1 \%)$ & 0.051 \\
\hline Transverse subpleural lines & $317(34.8 \%)$ & $43(33.8 \%)$ & $29(31.1 \%)$ & $6(8.3 \%)$ & $1(3.5 \%)$ & 0.01 \\
\hline Large vessel sign & 354 (38.9\%) & $38(29.9 \%)$ & $21(22.6 \%)$ & $12(16.6 \%)$ & $9(32.1 \%)$ & 0.51 \\
\hline Dense vessel sign & 169 (18.6\%) & $23(18.1 \%)$ & $12(12.9 \%)$ & $21(29.1 \%)$ & $11(39.2 \%)$ & 0.05 \\
\hline Pneumomediastinum & $9(0.09 \%)$ & $0(0 \%)$ & $-(0 \%)$ & $1(1.3 \%)$ & $2(7.1 \%)$ & 0.01 \\
\hline Pneumothorax & $6(0.06 \%)$ & $0(0 \%)$ & $-(0 \%)$ & $1(1.3 \%)$ & $2(7.1 \%)$ & 0.01 \\
\hline Mediastinal lymphadenopathy & $71(7.8 \%)$ & $1(0.07 \%)$ & $-(0 \%)$ & $2(2.7 \%)$ & $3(10.7 \%)$ & \\
\hline
\end{tabular}
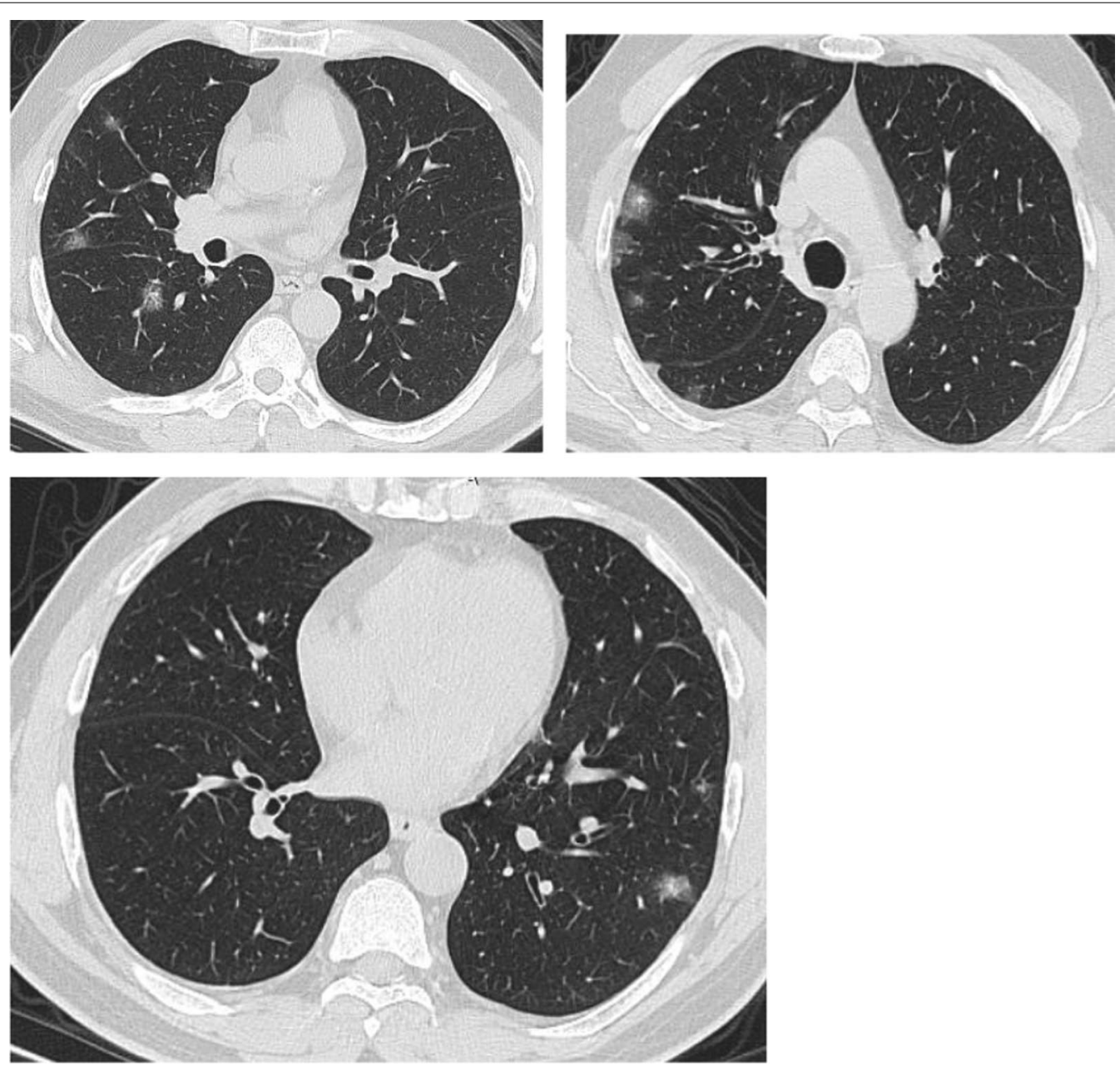

Fig. 14 Female patient aged 21 years, with multiple nodular lesions and halo sign 


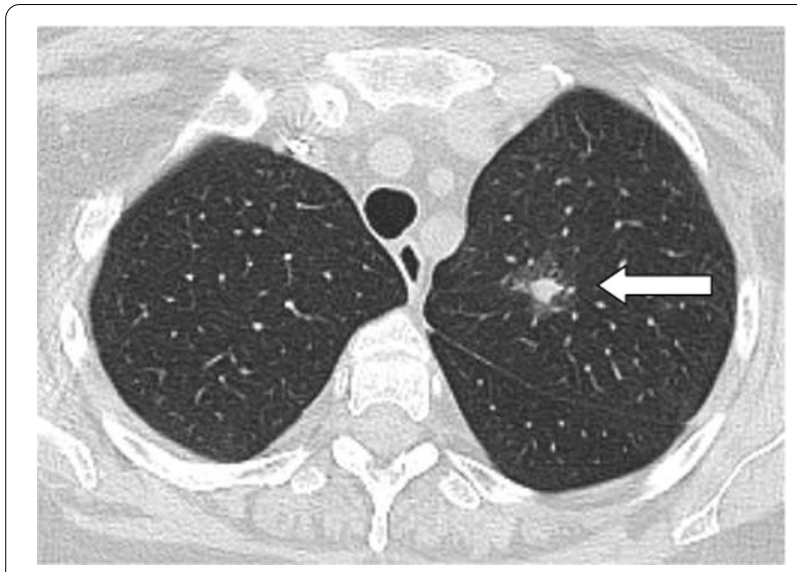

Fig. 15 Female patient aged 47 years, with single nodule with Halo sign

The reversed halo sign was reported in $10.1 \%$ of patients included in the study. The reversed halo sign was not reported in any case with severe pneumonia in the study by Zhan et al. [44]. Parry et al. [45] reported reversed halo sign in $21 \%$ of patients with mild disease and in only $5 \%$ of patients with severe disease, but the difference was statistically insignificant. In the current study, the reversed halo sign was more common in patients with favorable diagnosis than patients with unfavorable diagnosis and the difference was statistically significant probably because this sign reflects partial clearing of the lesions leaving an area of low attenuation.

The sub-pleural lines were reported frequently in the current study (317 patients, 34.8\%) of patients included in the study. The reported incidence in literature is $17-28 \%$ [33]. The sub-pleural lines were reported more frequently in patients with good prognosis, with statistically significant difference (0.01). The appearance of sub-pleural lines may indicate triggering of reparative process, and most likely fibrotic in nature [52]. $\mathrm{Li}$ et al. [53] reported sub-pleural lines more frequently in patients with severe disease, but the difference was statistically insignificant.

We reported two signs in the pulmonary vessels in the current study, the large vessel sign and the dense vessel sign. The large vessel sign showed no significant difference between patients with favorable and unfavorable prognosis, while the dense vessel sign
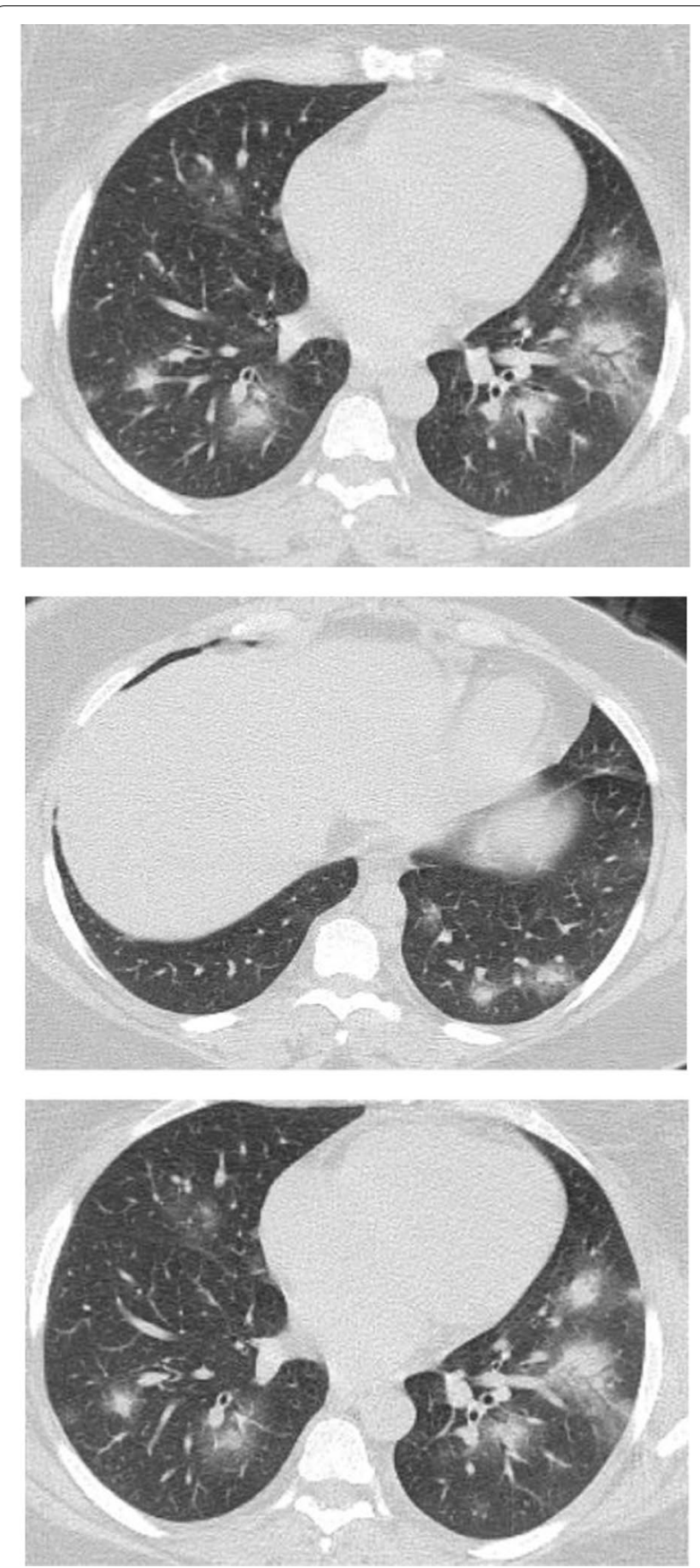

Fig. 16 Male patient, aged 25 years, with halo sign 7 days after onset of symptoms, with good prognosis 

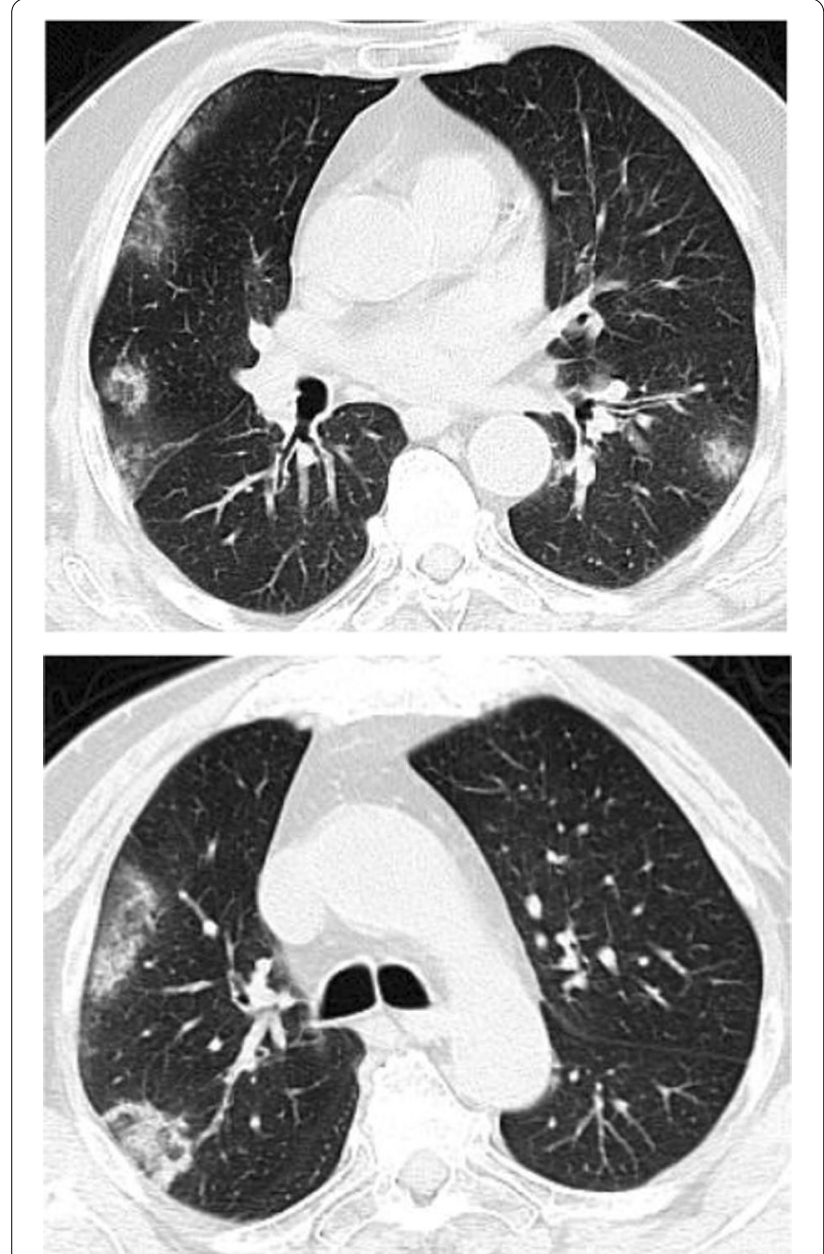

Fig. 17 Male patient, aged 32 years, with multiple subpleural patches with reversed halo sign. Most lesions were nodular in shape. This pattern carried a good prognosis in the current study

was reported more in patients with unfavorable prognosis, with statistically significant difference. The vascular enlargement sign results from injury of capillary endothelial cells and alveolar epithelial cells. The dense vessel sign is probably related to increased blood viscosity or localized arterial thrombosis which results from inflammatory cytokines. The dense vessel sign may warrant the use of anticoagulation or the increase in its dose. Ackermann et al. [54] reported vascular abnormalities in patients died from COVID19 pneumonia including localized thrombosis and microangiopathy.

In the current study, most patients with un-favorable prognosis had high CT severity score $(38 \%$ of patients had score $>18$, and $43 \%$ had score 9-17). Our results are consistent with previous reports $[9$,
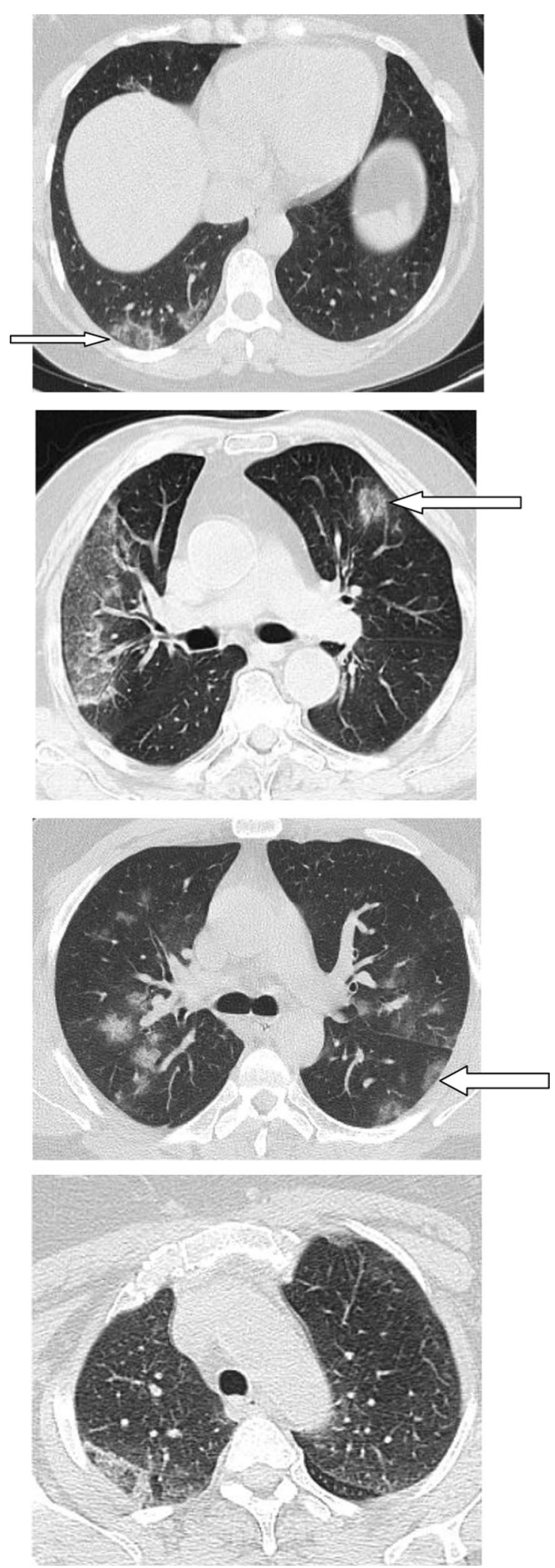

Fig. 18 Reversed halo sign in four different patients 

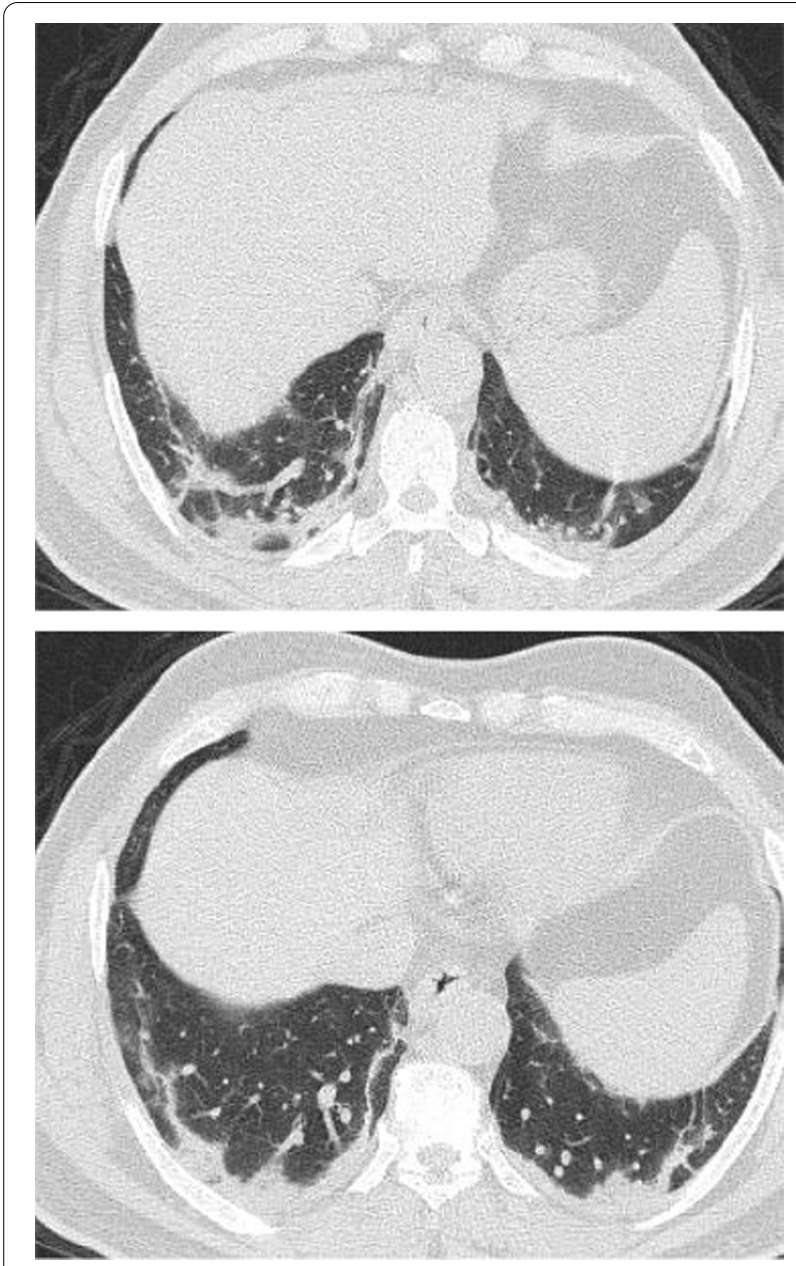

Fig. 19 Male patient aged 34 years, with multiple subpleural dense lesions with transverse subpleural lines

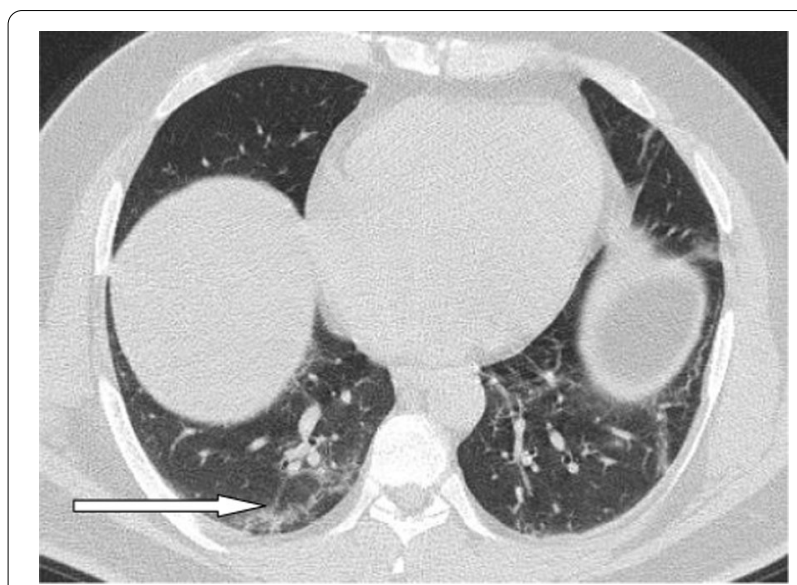

Fig. 20 Female patient, 32 years old with sub-pleural lines, peripheral and posterior, with subpleural transparent line

reported a positive correlation between the CT severity score and the increase in D dimer, severity of lymphopenia, increase oxygen requirement and the death rate. All these changes reflect the direct alveolar damage by the virus and the vascular changes [57].

There were some limitations of the study. First, we didn't correlate the CT findings with the duration of symptoms or onset of the disease. Second, we used only the CT findings in the initial CT scan, follow-up CT scans were not investigated and did not correlate with the disease progression. Third, we did not take in consideration the type and quality of medical treatment for each patient. Fourth, we did not perform multivariate statistical analysis.

\section{Conclusion}

Our results confirm the important role of the initial CT findings in the prediction of clinical outcome and shortterm prognosis. Some signs like subpleural lines, halo sign, reversed halo sign and nodular shape of the lesions predict mild disease and favorable prognosis. The crazy paving sign, dense vessel sign, consolidation, diffuse shape and high severity score predict more severe disease and probably warrant early hospitalization. The high severity score is most important in prediction of unfavorable prognosis. The nodular shape of the lesions is the most important predictor of good prognosis. 
Table 4 Distribution of CT severity score among all patients

\begin{tabular}{|c|c|c|c|c|c|c|}
\hline & All patients $(910)$ & $\begin{array}{l}\text { Stable patients } \\
(127 / 320)\end{array}$ & $\begin{array}{l}\text { Hospitalized stable } \\
\text { patients }(93 / 320)\end{array}$ & $\begin{array}{l}\text { Patients needed ICU } \\
(72 / 320)\end{array}$ & Died (28/320) & $P$ value \\
\hline Score 1-8 & $329(36.2 \%)$ & $73(57.5 \%)$ & $41(44.1 \%)$ & $14(19.4 \%)$ & $5(17.8 \%)$ & $<0.01$ \\
\hline Score 9-17 & $417(45.8 \%)$ & 49(38.6\%) & $36(33.5 \%)$ & $35(48.6 \%)$ & $8(28.5 \%)$ & 0.15 \\
\hline Score 18-25 & $164(18.02 \%)$ & $5(3.9 \%)$ & $16(14.8 \%)$ & $23(31.9 \%)$ & 15(53.3\%) & $<0.001$ \\
\hline
\end{tabular}

\section{Abbreviations}

GGO: Ground glass opacity; CTSS: Computed tomography severity score: COVID-19: Corona virus disease 2019; RT-PCR: Reverse transcription polymerase chain reaction.

\section{Acknowledgements}

None.

\section{Authors' contributions}

$\mathrm{MH}$ conceived of the study, interpretation of $\mathrm{CT}$ findings, participated in its design and coordination, drafted the manuscript, and carried out radiological results. TD and DE participated in the design of the study and sequence alignment and helped in drafting the results and followed up the patients and the correlation with the clinical picture and short-term prognosis. All authors have read and approved the final manuscript.

\section{Funding}

None.

\section{Availability of data and materials}

Data are available upon reasonable request.

\section{Declarations}

\section{Ethics approval and consent to participate}

The study was approved by the local ethics committee of Tanta University and informed written was waived. The reference number is not available.

\section{Consent for publication}

Not applicable.

\section{Competing interests}

The authors declare that they have no competing interests.

\section{Author details}

${ }^{1}$ Radiology Department, Faculty of Medicine, Tanta University, Tanta, Egypt.

${ }^{2}$ Faculty of Medicine, Tanta University, Tanta, Egypt.

Received: 18 May 2021 Accepted: 26 December 2021

Published online: 04 January 2022

\section{References}

1. Elsevier. Novel Coronavirus Information enter. ElsevierConnect. Archived from the original on 30 January 2020.Retrieved 15 March 2020

2. Coronavirus in Africa tracker. bbc.co.uk. Retrieved 4 December 2020

3. Kim H, Hong H, Yoon SH (2020) Diagnostic performance of CT and reverse transcriptase polymerase chain reaction for coronavirus disease 2019: a meta-analysis. Radiology 296(3):E145-E155

4. World Health Organization. Laboratory testing for 2019 novel coronavirus (2019-nCoV) in suspected human cases .https://www.who.int/publicatio ns-detail/laboratory-testing-for-2019-novel-coronavirus-in-suspectedhuman-cases-20200117.Published March 19, 2020. Accessed June 6, 2020
5. Sethuraman N, Jeremiah SS, Ryo A (2020) Interpreting diagnostic tests for SARS-CoV-2. JAMA 323:2249-2251. https://doi.org/10.1001/jama.2020. 8259

6. Shi H, Han X, Jiang N, Cao Y, Alwalid O, Gu J, Fan Y, Zheng C (2020) Radiological findings from 81 patients with COVID-19 pneumonia in Wuhan, China: a descriptive study. Lancet Infect Dis 20(4):425-434. https://doi. org/10.1016/S1473-3099(20)30086-4

7. Pan Y, Guan H, Zhou S, Wang Y, Li Q, Zhu T, Hu Q, Xia L (2020) Initial CT findings and temporal changes in patients with the novel coronavirus pneumonia (2019-nCoV): a study of 63 patients in Wuhan, China. Eur Radiol 30(6):3306-3309. https://doi.org/10.1007/s00330-020-06731-X

8. Song F, Shi N, Shan F, Zhang Z, Shen J, Lu H, Ling Y, Jiang Y, Shi Y (2020) Emerging 2019 novel coronavirus (2019-nCoV) pneumonia. Radiology 295(1):210-217. https://doi.org/10.1148/radiol.2020200274

9. Duan YN, Qin J (2020) Pre- and post treatment chest CT findings: 2019 novel coronavirus (2019-nCoV) pneumonia. Radiology 295(1):21. https:// doi.org/10.1148/radiol.2020200323

10. Guan WJ, Ni ZY, Hu Y et al (2020) Clinical characteristics of coronavirus Disease 2019 in China. N Engl J Med 382:1708-1720. https://doi.org/10. 1056/NEJMoa2002032

11. Bernheim A, Mei X, Huang M, Yang Y, Fayad ZA, Zhang N, Diao K, Lin B, Zhu X, Li K, Li S, Shan H, Jacobi A, Chung M (2020) Chest CT findings in coronavirus disease-19 (COVID-19): relationship to duration of infection. Radiology 295(3):200463. https://doi.org/10.1148/radiol.2020200463

12. Ai T, Yang Z, Hou H, Zhan C, Chen C, Lv W, Tao Q, Sun Z, Xia L (2020) Correlation of chest CT and RT-PCR testing for coronavirus disease 2019 (COVID-19) in China: a report of 1014 cases. Radiology 296(2):E32-E40. https://doi.org/10.1148/radiol.2020200642

13. Lei J, Li J, Li X, Qi X (2020) CT imaging of the 2019 novel coronavirus (2019-nCoV) pneumonia. Radiology 295(1):18

14. Caruso D, Zerunian M, Polici M et al (2020) Chest CT features of COVID19 in Rome, Italy. Radiology 296:E79-E85. https://doi.org/10.1148/ radiol.2020201237

15. Wang J, Liu J, Wang Y, Liu W, Chen X, Sun C, Shen X, Wang Q, Wu $Y$, Liang W, Ruan L (2020) Dynamic changes of chest CT imaging in patients with corona virus disesase-19 (COVID-19). Zhejiang Da XueXueBao Yi Xue Ban 49(1):191-197. https://doi.org/10.3785/j.issn. 1008-9292.2020.02.03

16. Wu J, Wu X, Zeng W et al (2020) Chest CT findings in patients with corona virus disease 2019 and its relationship with clinical features. Investig Radiol 55:257-261

17. Xu X, Yu C, Qu J et al (2020) (2020) Imaging and clinical features of patients with 2019 novel coronavirus SARS-CoV-2. Eur J Nucl Med Mol Imaging 47:1275-1280

18. Chung M, Bernheim A, Mei X et al (2020) CT imaging features of 2019 novel coronavirus (2019-nCoV). Radiology 295(1):202-207. https://doi. org/10.1148/radiol.2020200230

19. Fang $Y$, Zhang $H, X u Y$, Xie J, Pang P, Ji W (2020) CT manifestations of two cases of 2019 novel coronavirus (2019-nCoV) pneumonia. Radiology 295(1):208-209. https://doi.org/10.1148/radiol.2020200280

20. Chen D, Jiang X, Hong Y, Wen Z, Wei S, Peng G, Wei X (2021) Can chest CT Features Distinguish Patients With Negative From Those With Positive Initial RT-PCR results for coronavirus disease (COVID-19)? AJR Am J Roentgenol 216(1):66-70. https://doi.org/10.2214/AJR.20.23012

21. Guan CS, Lv ZB, Yan S et al (2020) Imaging features of coronavirus disease 2019 (COVID-19): evaluation on thin-section CT. Acad Radiol 27(5):609-613. https://doi.org/10.1016/j.acra.2020.03.002 
22. Adams HJA, Kwee TC, Yakar D, Hope MD, Kwee RM (2020) Chest CT imaging signature of coronavirus disease 2019 infection: In pursuit of the scientific evidence. Chest 158(5):1885-1895. https://doi.org/10. 1016/j.chest.2020.06.025

23. Hafez MAF (2020) The mean severity score and its correlation with common computed tomography chest manifestations in Egyptian patients with COVID-2019 pneumonia. Egypt J Radiol Nucl Med 51:254. https://doi.org/10.1186/s43055-020-00368-y

24. Dawoud MM, Dawoud TM, Ali NYA et al (2020) Chest CT in COVID-19 pneumonia: a correlation of lung abnormalities with duration and severity of symptoms. Egypt J Radiol Nucl Med 51:246. https://doi.org/ 10.1186/s43055-020-00359-Z

25. Sabri YY, Fawzi MMT, Nossair EZ et al (2020) CT findings of 795 COVID19 positive cases: a multicenter study in Egypt. Egypt J Radiol Nucl Med 51:237. https://doi.org/10.1186/s43055-020-00351-7

26. Achour A, Dkhil Q, Saadet J et al (2020) Chest CT-scan finding of asymptomatic covid-19 pneumonia: a prospective 542 patients single center study. Pan Afr Med J 36:257. https://doi.org/10.11604/pamj. 2020.36.257.236

27. Hasni M, Farahat Z, Abdeljelil A, Marzouki K, Aoudad M, Tlemsani Z, Megdiche K, Ngote N (2020) An efficient approach based on 3D reconstruction of CT scan to improve the management and monitoring of COVID-19 patients. Heliyon 6(11):e05453. https://doi.org/10.1016/j. heliyon.2020.e05453

28. Zhou F, Yu T, Du R et al (2020) Clinical course and risk factors for mortality of adult inpatients with COVID-19 in Wuhan, China: a retrospective cohort study. Lancet 395:1054-1062. https://doi.org/10.1016/S01406736(20)30566-3

29. Li X, Xu S, Yu M, Wang K, Tao Y, Zhou Y, Shi J, Zhou M, Wu B, Yang Z, Zhang C, Yue J, Zhang Z, Renz H, Liu X, Xie J, Xie M, Zhao J (2020) Risk factors for severity and mortality in adult COVID-19 inpatients in Wuhan. J Allergy Clin Immunol 146(1):110-118. https://doi.org/10. 1016/j.jaci.2020.04.006

30. Yu M, Xu D, Lan L, Tu M, Liao R, Cai S, Cao Y, Xu L, Liao M, Zhang X, Xiao SY, Li Y, XU H (2020) Thin-section chest CT imaging of COVID-1 9 Pneumonia: a comparison between patients with mild and severe disease. Radiol Cardiothorac Imaging 2(2):e200126. https://doi.org/10.1148/ ryct.2020200126

31. Tabatabaei SMH, Talari H, Moghaddas F, Rajebi H (2020) CT Features and short-term prognosis of COVID-19 pneumonia: a single-center study from Kashan, Iran. Radiol Cardiothorac Imaging 2(2):e200130. https://doi.org/10.1148/ryct.2020200130

32. Colombi D, Bodini FC, Petrini M, Maffi G, Morelli N, Milanese G, Silva M, Sverzellati N, Michieletti E (2020) Well-aerated lung on admitting chest CT to predict adverse outcome in covid-19 pneumonia. Radiology 296(2):E86-E96. https://doi.org/10.1148/radiol.2020201433

33. Zhao W, Zhong Z, Xie X, Yu Q, Liu J (2020) Relation between chest CT findings and clinical conditions of coronavirus disease (COVID-19) pneumonia: a multicenter study. AJR Am J Roentgenol 214:1072-1077. https://doi.org/10.2214/AJR.20.22976

34. Li K, Fang Y, Li W, Pan C, Qin P, Zhong Y, Liu X, Huang M, Liao Y, Li S (2020) CT image visual quantitative evaluation and clinical classification of coronavirus disease (COVID-19). Eur Radiol 30(8):4407-4416. https://doi.org/10.1007/s00330-020-06817-6

35. Pan F, Ye T, Sun P, Gui S, Liang B, Li L, Zheng D, Wang J, Hesketh RL, Yang L, Zheng C (2020) Time course of lung changes at chest CT during recovery from coronavirus disease 2019 (COVID-19). Radiology 295:715-721

36. Liu F, Li L, Xu M et al (2020) Prognostic value of interleukin-6, C-reactive protein, and procalcitonin in patients with COVID-19. J Clin Virol 127:104370. https://doi.org/10.1016/j.jcv.2020.104370

37. Lippi G, Favaloro EJ (2020) D-dimer is associated with severity of coronavirus disease 2019: a pooled analysis. Thromb Haemost 120:876-878. https://doi.org/10.1055/s-0040-1709650

38. Garg M, Gupta P, Maralakunte M, Kumar-M P, Sinha A, Kang M, Agarwal R, Sandhu MS (2021) Diagnostic accuracy of CT and radiographic findings for novel coronavirus 2019 pneumonia: Systematic review and metaanalysis. Clin Imaging 72:75-82. https://doi.org/10.1016/j.clinimag.2020. 11.021

39. Zarifian A, GhasemiNour M, AkhavanRezayat A, RahimzadehOskooei R, Abbasi B, Sadeghi R (2021) Chest CT findings of coronavirus disease 2019
(COVID-19): A comprehensive meta-analysis of 9907 confirmed patients. Clin Imaging 70:101-110. https://doi.org/10.1016/j.clinimag.2020.10.035

40. Wu J, Pan J, Teng D, Xu X, Feng J, Chen YC (2020) Interpretation of CT signs of 2019 novel coronavirus (COVID-19) pneumonia. Eur Radiol 30(10):5455-5462. https://doi.org/10.1007/s00330-020-06915-5

41. Huang C, Wang Y, Li X et al (2020) Clinical features of patients infected with 2019 novel coronavirus in Wuhan, China. Lancet 395(10223):497506. https://doi.org/10.1016/S0140-6736(20)30183-5

42. Wong HYF, Lam HYS, Fong AH et al (2020) Frequency and distribution of chest radiographic findings in patients. Radiology 296(2):E72-E78. https://doi.org/10.1148/radiol.2020201160

43. Zhou S, Zhu T, Wang Y, Xia L (2020) Imaging features and evolution on CT in 100 COVID-19 pneumonia patients in Wuhan, China. Eur Radiol 30(10):5446-5454. https://doi.org/10.1007/s00330-020-06879-6

44. Zhan X, Chen Z, Hu H, Yang Y, Wu K, Cheng Z, Liu B (2021) Dandelion and focal crazy paving signs: the lung $C T$ based predictors for evaluation of the severity of coronavirus disease. Curr Med Res Opin 37(2):219-224. https://doi.org/10.1080/03007995.2020.1846173

45. Parry AH, Wani AH, Shah NN, Yaseen M, Jehangir M (2020) Chest CT features of coronavirus disease-19 (COVID-19) pneumonia: Which findingson initial CT can predict an adverse short-termoutcome? BJR 2:20200016

46. Han R, Huang L, Jiang H, Dong J, Peng H, Zhang D (2020) Early clinical and CT manifestations of coronavirus disease 2019 (COVID-19) pneumonia. Am J Roentgenol 215:338-343

47. Zhang N, Xu X, Zhou LY, Chen G, Li Y, Yin H, Sun Z (2020) Clinical characteristics and chest $C T$ imaging features of critically ill COVID19 patients. Eur Radiol 30(11):6151-6160. https://doi.org/10.1007/ s00330-020-06955-X

48. Salehi S, Abedi A, Balakrishnan S, Gholamrezanezhad A (2020) Coronavirus disease 2019 (COVID-19): A systematic review of imaging findings in 919 patients. AJR Am J Roentgenol 215(1):87-93. https://doi.org/10.2214/ AJR.20.23034

49. Gillespie M, Flannery P, Schumann JA, Dincher N, Mills R, Can A (2020) Crazy-paving: a computed tomographic finding of coronavirus disease 2019. Clin Pract Cases Emerg Med 4(3):461-463. https://doi.org/10.5811/ cpcem.2020.5.47998

50. Meiler S, Schaible J, Poschenrieder F, Scharf G, Zeman F, Rennert J, Pregler B, Kleine H, Stroszczynski C, Zorger N, Hamer OW (2020) Can CT performed in the early disease phase predict outcome of patients with COVID 19 pneumonia? Analysis of a cohort of 64 patients from Germany. Eur J Radiol 131:109256. https://doi.org/10.1016/j.ejrad.2020.109256

51. Pinto PS (2004) The CT halo sign. Radiology 230(1):109-110

52. Nagpal P, Narayanasamy S, Vidholia A, Guo J, Shin KM, Lee CH et al (2020) Imaging of COVID-19 pneumonia: patterns, pathogenesis, and advances. Br J Radiol 93:20200538

53. Li K, Wu J, Wu F, Guo D, Chen L, Fang Z et al (2020) The clinical and chest CT features associated with severe and critical COVID-19 pneumonia. Investig Radiol 55:327-331. https://doi.org/10.1097/RLI.0000000000 000672

54. Ackermann M, Verleden SE, Kuehnel M et al (2020) Pulmonary vascular endothelialitis, thrombosis, and angiogenesis in Covid-19. N Engl J Med 383:120-128

55. Xie L, Hou K, Xu H, Fu H, Xu R, Liu H, Zhou Z, Li Z, Yang M, Guo Y (2020) Chest CT features and progression of patients with coronavirus disease 2019. Br J Radiol 93(1116):20200219. https://doi.org/10.1259/bjr.20200 219

56. Francone M, lafrate F, Masci GM et al (2020) Chest CT score in COVID-19 patients: correlation with disease severity and short-term prognosis. Eur Radiol 30(12):6808-6817. https://doi.org/10.1007/s00330-020-07033-y

57. Saeed GR, Gaba W, Shah A (2020) Correlation between chest CT severity scores and the clinical parameters of adult patients with Covid-19 pneumonia. Radiol Res Pract. https://doi.org/10.1101/2020.10.15.20213058

\section{Publisher's Note}

Springer Nature remains neutral with regard to jurisdictional claims in published maps and institutional affiliations. 